${ }^{1}$ Department of Microbiology, Immunology and Glycobiology, Institute of Laboratory Medicine, Lund University, Lund, Sweden.

${ }^{2}$ Nephrology Service, Department of Paediatrics, KK Hospital, Singapore Singapore.

凶e-mail: catharina.svanborg@ med.lu.se

https://doi.org/10.1038 s41585-021-00477-x

\title{
Molecular determinants of disease severity in urinary tract infection
}

\author{
Ines Ambite $\mathbb{B}^{1}$, Daniel Butler $\mathbb{D}^{1}$, Murphy Lam Yim Wan', Therese Rosenblad', \\ Thi Hien Tran ${ }^{1}$, Sing Ming Chao ${ }^{2}$ and Catharina Svanborg ${ }^{1 凶}$
}

Abstract | The most common and lethal bacterial pathogens have co-evolved with the host. Pathogens are the aggressors, and the host immune system is responsible for the defence. However, immune responses can also become destructive, and excessive innate immune activation is a major cause of infection-associated morbidity, exemplified by symptomatic urinary tract infections (UTIs), which are caused, in part, by excessive innate immune activation. Severe kidney infections (acute pyelonephritis) are a major cause of morbidity and mortality, and painful infections of the urinary bladder (acute cystitis) can become debilitating in susceptible patients. Disease severity is controlled at specific innate immune checkpoints, and a detailed understanding of their functions is crucial for strategies to counter microbial aggression with novel treatment and prevention measures. One approach is the use of bacterial molecules that reprogramme the innate immune system, accelerating or inhibiting disease processes. A very different outcome is asymptomatic bacteriuria, defined by low host immune responsiveness to bacteria with attenuated virulence. This observation provides the rationale for immunomodulation as a new therapeutic tool to deliberately modify host susceptibility, control the host response and avoid severe disease. The power of innate immunity as an arbitrator of health and disease is also highly relevant for emerging pathogens, including the current COVID-19 pandemic.

Infections remain a major cause of mortality worldwide and the long-term consequences can be severe for those who survive. The cycle of infection is one of 'bad bugs', susceptible patients, acute disease and debilitating sequelae $^{1}$. Pathogens are the aggressors, and the host immune system is responsible for the defence. However, the host immune system can also become destructive, and excessive innate immune activation is a major cause of infection-associated morbidity ${ }^{2}$.

Innate immunity provides an immediate antimicrobial defence to all classes of plant and animal life $\mathrm{e}^{3-5}$. Through specific recognition and activation strategies, the immune response targets and eliminates pathogens while sustaining symbiosis with the commensal flora; an impressive level of precision ${ }^{6}$. The defence is executed by a variety of mechanisms that also trigger inflammation and disease symptoms. Fortunately, this response is mostly transient and health is restored, but in susceptible hosts, a lack of molecular control can create exaggerated inflammatory states, severe disease, mortality and in some cases chronic inflammatory disorders.

Host susceptibility can be attributed, in part, to shortcomings of the innate immune system, which provides opportunities for the infecting pathogens ${ }^{7,8}$ (FIG. 1). Detailed molecular insights now reveal how a subset of susceptible individuals develop severe infections, recurrences and tissue damage. The crucial role of innate immunity for host susceptibility is apparent in the urinary tract, where some of these defence mechanisms were first identified ${ }^{9,10}$. Urinary tract infections (UTIs), are extremely common and increasingly difficult to treat owing to antimicrobial resistance ${ }^{11-13}$. At least half of all women experience acute cystitis, an infection of the urinary bladder characterized by pain, dysuria and frequency of voiding ${ }^{14-17}$ (FIG. 2). A subset of these women develop recurrent cystitis, which seriously impairs quality of life. Men are substantially less affected than women (5-8 per 10,000) $)^{18,19}$. Acute pyelonephritis (APN) is a serious, potentially life-threatening infection of the kidneys, accompanied by urosepsis in about $30 \%$ of adults ${ }^{20-23}$ (FIG. 2). In childhood, APN is at least as common as pneumonia, and can delay renal growth or cause focal renal tissue damage, increasing the risk of long-term morbidities such as hypertension and renal failure $^{24-27}$. At present, no reliable tools exist to predict the risk of recurrent APN, renal tissue damage or other detrimental effects of infection.

Fortunately, important insights into molecular determinants of UTI susceptibility offer new solutions to this long-standing dilemma ${ }^{6,28-34}$. This Review highlights 


\section{Key points}

- Host resistance to infection is maintained by tight control of the immune response. If uncontrolled, excessive immune activation can lead to severe disease and inefficient microbial clearance.

- Urinary tract infections (UTIs) are a major cause of acute disease morbidity and mortality, as well as chronic sequelae. Uropathogens trigger innate immune responses in the kidneys (acute pyelonephritis) or the urinary bladder (acute cystitis).

- Disease severity is regulated at specific innate immune checkpoints, which control transcription and critical antimicrobial effector functions.

- Distinct susceptibility genes distinguish the two forms of symptomatic UTI through different mechanisms of immune hyperactivation.

- Bacteria with reduced virulence are carried asymptomatically and enhance their fitness by actively inhibiting the host response.

- This level of molecular resolution in UTI offers an exciting potential for improved diagnosis and novel immunomodulatory therapies.

advances in our understanding of the molecular determinants of UTI pathogenesis, focusing on specific host susceptibility factors and their consequences. The molecular basis of disease is discussed, as well as the key events that define disease severity, with different characteristics in the kidneys and the bladder. By contrast, we also describe asymptomatic bacteriuria $(\mathrm{ABU})$ and the molecular characteristics that explain this protective state. These novel findings have major implications for the precision of future diagnostic and therapeutic practices, especially the use of immunotherapy to reduce the excessive immune activation and restore a functional defence $^{33-36}$.

\section{Asymptomatic bacteriuria}

The urinary tract is a preferred niche for bacterial growth, similar to the intestinal and respiratory tracts, which harbour a rich microflora. Certain bacterial strains, attenuated for virulence, can establish a 'symbiotic state' in individual hosts and persist long term ${ }^{37,38}$. No evidence exists suggesting that $\mathrm{ABU}$ increases the risk of symptomatic infection - quite the contrary, in fact $^{15,39,40}$. Epidemiological studies have demonstrated that $\mathrm{ABU}$ reduces the risk of symptomatic infection and recommendations from the Infectious Diseases Society of America (IDSA) and European Association of Urology (EAU) are to leave ABU untreated ${ }^{41,42}$.

$A B U$ was discovered when urine cultures were first performed in the general population and defined as growth of $>10^{5}$ colony-forming units (cfu) per millilitre of urine in an asymptomatic individual ${ }^{14,15}$. Asymptomatic bacterial carriage was found in $\sim 1 \%$ of schoolgirls, $2-10 \%$ of pregnant women and $>20 \%$ of individuals $>70$ years of age $e^{21,43,44}$ (FIG. 2). Long-term follow-up studies demonstrated that asymptomatic carriage is protective, as the frequency of symptomatic UTI recurrences is reduced in patients with untreated $A B U$ compared with patients treated with antibiotics ${ }^{39,45}$. In a controlled prospective study of ABU, children treated with antibiotics were at an increased risk of symptomatic episodes compared with patients in whom ABU was left untreated ${ }^{46}$. This observation is the rationale for deliberately establishing $\mathrm{ABU}$ in patients who are refractory to other therapies ${ }^{37,47-49}$. Intravesical inoculation of ABU strains, such as Escherichia coli 83972, has been used successfully and protection has been demonstrated in various studies, including a placebo-controlled clinical trial ${ }^{49-52}$. After deliberate inoculation with E. coli 83972 the time to a symptomatic episode was prolonged and the likelihood was decreased (11.3 versus 5.7 months; 15 versus 73 recurrences after 12 months) $)^{50}$. A friendly coexistence between bacteria and host, therefore, seems to be a highly desirable outcome $\mathrm{e}^{53-55}$.

\section{Adaptation strategies of bacteria and host}

$\mathrm{ABU}$ provides a very useful model for studying molecular determinants of asymptomatic carriage and symbiosis in a human ecological context. The asymptomatic carrier state allows bacteria to persist without evoking a destructive host response and at least four different adaptation strategies have been identified (FIG. 3). First, most ABU strains have a virulence-attenuated phenotype and successfully avoid triggering the innate immune response ${ }^{56}$. Second, ABU strains actively suppress host gene expression, for example, by inhibiting RNA polymerase II, including genes crucial for the innate host defence against UTI ${ }^{36,57}$. Third, attenuating Toll-like receptor 4 (TLR4) promoter polymorphisms reduce innate immune activation and downstream signalling in patients with $\mathrm{ABU}^{58,59}$. Mutations or deletions affecting Tlr4 abrogate innate immune activation by E. coli in mice and create an ABU-like state ${ }^{60}$. Fourth, the mucosal TLR4 response is attenuated in the human urinary tract mucosa, owing to a lack of pattern recognition co-receptors for lipopolysaccharides (LPSs) such as CD14 (REFS ${ }^{61,62}$ ).

Virulence attenuation. Early population-based studies revealed that most $A B U$ strains lack the virulence factors that typically define APN strains, including $P$ fimbriae ${ }^{63-65}$. When cellular infection models were first established, most $\mathrm{ABU}$ strains were shown not to adhere to urothelial cells and to lack virulence-associated adherence factors such as P fimbriae ${ }^{63,66,67}$. Two categories of $A B U$ strains can now be distinguished: 'primary ABU strains', which resemble the commensal E. coli flora, and 'attenuated pathogens', which share overall sequence characteristics with uropathogenic strains but have lost virulence, presumably by reductive evolution leading to a sequential loss of virulence gene function, caused by deletions and point mutations $\mathrm{s}^{53,56,65}$. Loss of pathogenicity island (PAI) genes can result in a complete or partial loss of virulence function, further strengthening the argument that the strains have evolved away from the virulent phenotype ${ }^{56}$. For example, attenuating mutations frequently affect fimbrial adhesins (P, type 1 , $\mathrm{S}$ and F1C), $\alpha$-haemolysin, aerobactin and other virulence genes ${ }^{54,67}$. The loss of the pathogenicity island marker malX, as well as iha and $o m p T$, is observed in $\mathrm{ABU}$ isolates ${ }^{68}$. ABU strains produce substantially fewer siderophores such as aerobactin and enterobactin and less frequently express $h l y A$ (which encodes a-haemolysin), iha and fyuA (a high-PAI marker gene) than virulent strains ${ }^{67}$.

The ABU strain E. coli 83972 has been used as a molecular model to study this gradual loss of virulence in human carriers. E. coli 83972 is characterized by a 


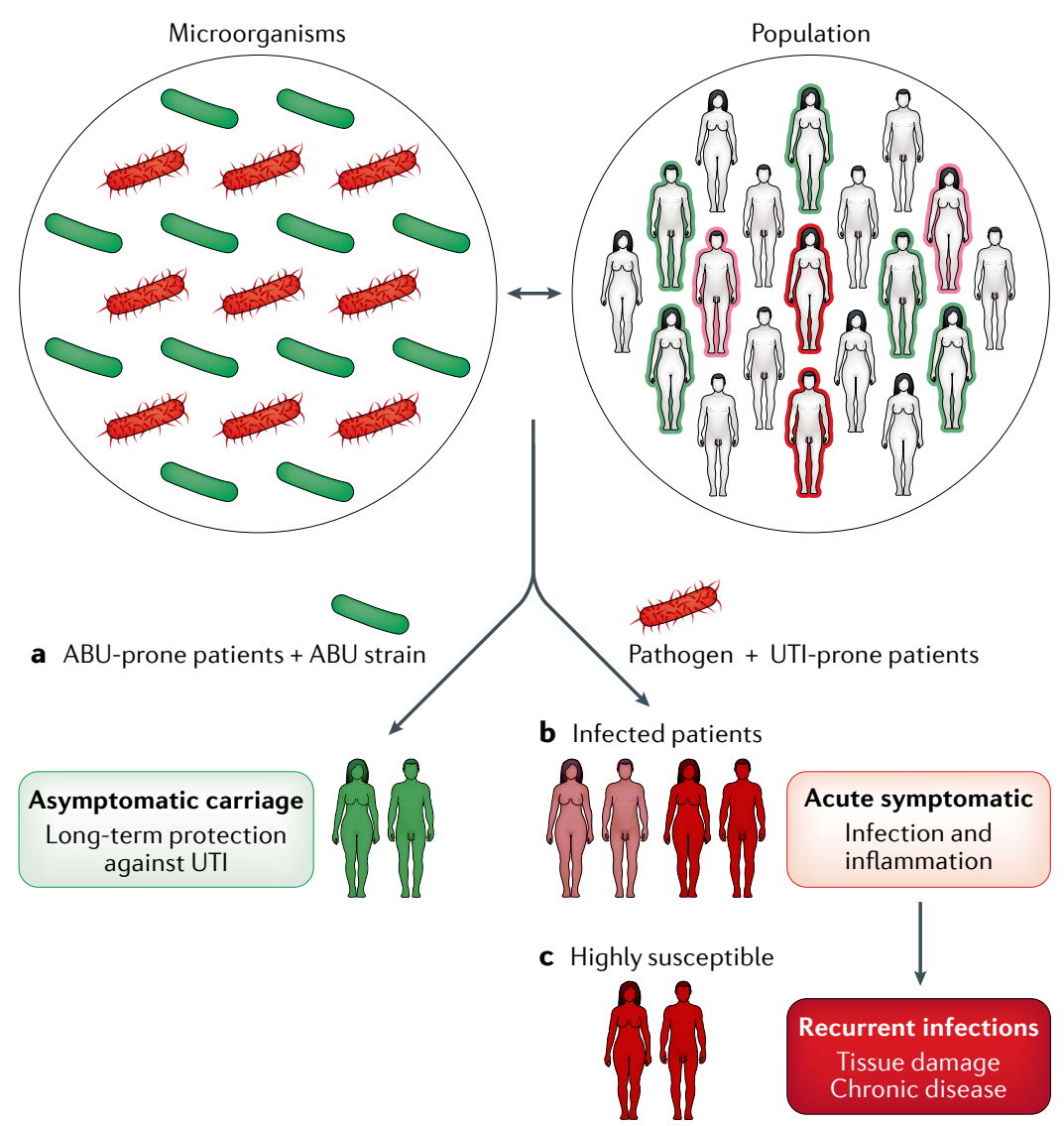

Fig. 1 | Susceptibility to urinary tract infection. Host susceptibility to urinary tract infection varies in the population, as does the virulence of bacteria that humans are exposed to. The majority of exposed individuals get rid of the bacteria without developing symptoms or bacteriuria. Three main outcomes of host-microorganism interaction can occur in the urinary tract. a | Asymptomatic bacteriuria (green) is a beneficial carrier state established by virulence-attenuated bacteria in active cross-talk with their hosts. $\mathbf{b}$ |Symptomatic infections occur in UTI-prone patients infected with pathogens. $\mathbf{c}$ |A subset of UTI-prone patients is highly susceptible and these individuals develop severe acute disease, recurrent infections and chronic disease states. $\mathrm{ABU}$, asymptomatic bacteriuria; UTI, urinary tract infection. smaller genome size than virulent strains of the same phylogroup and specific virulence genes are inactivated by deletions (such as fimEAIC), multiple point mutations (such as papG and $f o c D$ ) and a premature stop codon (such as $h l y A)^{56,69}$. Importantly, virulence attenuation has been shown to continue in human hosts carrying $E$. coli $83972\left(\mathrm{REFS}^{50,53,70}\right)$. During ABU, rapid and distinct bacterial genome alterations occur in a host-specific manner, involving functionally important genes such as regulators of gene expression, metabolism and virulence ${ }^{53}$. Interestingly, the host-specific mutation pattern was reproduced in patients who received the same strain on several occasions, suggesting a strong, host-specific adaptation pattern of $\mathrm{ABU}$ strains.

Inhibition of host gene expression by targeting RNA Pol II phosphorylation. $\mathrm{ABU}$ strains were further shown to actively modify the host environment in which they persist. Changes in gene expression were detected by studying RNA samples obtained from patients inoculated with E. coli $83972\left(\right.$ REF. $\left.^{57}\right)$. Interestingly, $>60 \%$ of all genes were inhibited after $24 \mathrm{~h}$ compared with the pre-inoculation sample in each patient, suggesting that bacteria actively modify the host response to promote their own survival.

Further investigation identified a mechanism used by $A B U$ strains to actively suppress RNA polymerase II (Pol II)-dependent gene expression in the host by regulating crucial steps in the Pol II transcription cycle ${ }^{57}$. The multi-protein Pol II complex catalyses the transcription of mRNA precursors and most snRNAs and microRNAs through a series of steps, called the RNA Pol II cycle $^{71-73}$. Phosphorylation of the C-terminal domain of the Pol II subunit RPB1 is required to initiate productive RNA elongation ${ }^{72}$. E. coli 83972 suppressed several transcriptional activators (including FOSB, CTNNB1 and TFAP2A), activated transcriptional repressors (including $D A C H 1, B A N P$ and $D D X 20$ ) and suppressed genes involved in transcription initiation and recognition of the TATA box-binding protein (TBP) $)^{57}$. Specifically, the $\mathrm{ABU}$ strain regulated promoter release and productive elongation by inhibiting the RNA Pol II phosphorylation complex and small nuclear RNAs (RN7SK, RNU6ATAC, RNA28S5). The frequency of Pol II inhibition was higher among $A B U$ strains and faecal strains than in APN strains, supporting an association with ABU and commensalism $^{57}$.

The bacterial $n l p D$ gene was identified as a key regulator of bacterial RNA Pol II inhibition in the host by using a loss-of-function mutant from an inoculated patient ${ }^{36}$. NlpD is a divisome-associated, outer membrane lipoprotein that activates the peptidoglycan hydrolase AmiC during bacterial cell separation ${ }^{74,75}$. These results suggest that the bacterial NlpD protein directly targets constituents of the Pol II phosphorylation complex ${ }^{36}$ (the Pol II subunit RPB1 and the phosphorylation complex adaptor, PAF1C; FIG. 4). NlpD was released by ABU strains followed by efficient transfer of the protein across host cell membranes ${ }^{36}$. This mechanism is fascinating as it enables bacteria to act directly on host cells by releasing proteins that modify the transcription machinery. In the case of NlpD from ABU strains, the bacterial protein inhibits transcription and suppresses excessive host innate immune responses. NlpD treatment was shown to reduce inflammation and enhance bacterial clearance from infected bladders in vivo when recombinant NlpD was injected intraperitoneally before intravesical $E$. coli infection $^{36}$. The findings suggest major therapeutic potential for NlpD as a modifier of inflammation and illustrate the potential of molecules of bacterial origin as immunomodulatory agents.

Attenuated TLR4 activation and mucosal pathogen recognition. Targeting of host receptors by pathogens alerts the host to the presence of the bacteria. Their virulence factors act as 'danger signals' and the host responds by activating the innate immune response, potentially leading to disease. By contrast, in $\mathrm{ABU}$, such responses are avoided and the relative inertia of the host mucosa has been associated with reduced innate immune recognition of the infecting bacteria.

Host recognition of Gram-negative bacteria has been extensively studied ${ }^{10,76,77}$. TLR4 controls the innate host response to Gram-negative bacterial infection 
generally, but with considerable complexity, depending on the pathogen and the site of infection ${ }^{77}$ (FIG. 3). Early studies in a mouse UTI model showed that Lps, later redefined as Tlr4 $\left(\mathrm{REF}^{10}{ }^{10}\right.$ ), is a major determinant of the host response to UTI ${ }^{9,78}$. However, the mechanism of TLR4 activation was shown to differ between epithelial cells in the mucosal lining of the urinary tract and monocytes, which had been used as a model ${ }^{62}$. Urothelial cells express TLR4, but not the co-receptors CD14 and MD2 (also referred to as LY96) and, as a result, LPS recognition is weak, unless soluble CD14 is present at the site of infection ${ }^{61,62}$. This lack of reactivity explains why ABU strains persist without creating a state of chronic inflammation in the urinary tract mucosa (FIC. 3; TABLE 1). Importantly, bacteria that express TLR4 agonists, such as P fimbriae, can override this unresponsiveness by engaging different TLR4 coreceptors, such as glycosphingolipids ${ }^{79}$. This mechanism provides mucosal membranes with a much needed, pathogen-specific solution for when to respond to bacteria in the lumen. If epithelial cells recognized LPS, the entire Gram-negative microflora would trigger TLR4 signalling and chronic inflammation in the intestine and at other mucosal sites.

Attenuating TLR4 promoter polymorphisms in patients with $A B U$. A protected, $\mathrm{ABU}$-like phenotype was first observed in $\mathrm{C} 3 \mathrm{H} / \mathrm{HeJ}$ mice, which carry a point mutation in the Toll/interleukin-1 receptor (TIR) domain of TLR4 (REFS ${ }^{9,58,59}$ ). Tlr4 ${ }^{-/-}$mice are protected from symptomatic UTI. Mice carrying single Tlr4 adaptor gene deletions $\left(\right.$ Trif $^{--}, M y D 88^{-/-}$) infected with

\section{a Acute pyelonephritis}
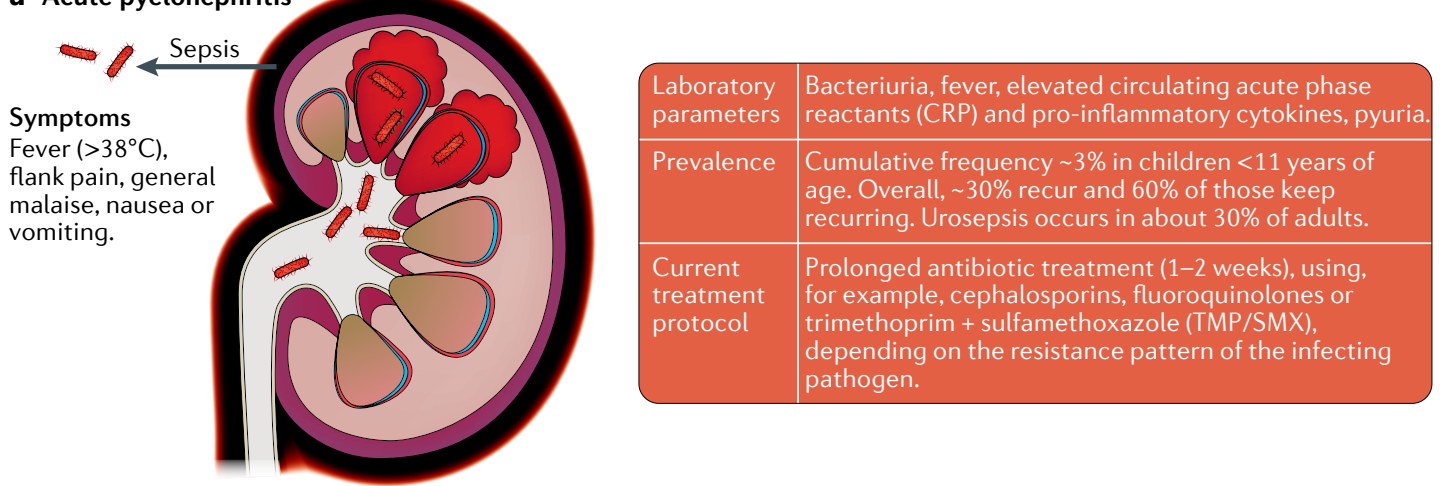

b Acute cystitis

Symptoms

Suprapubic pain, dysuria, frequency, urgency.

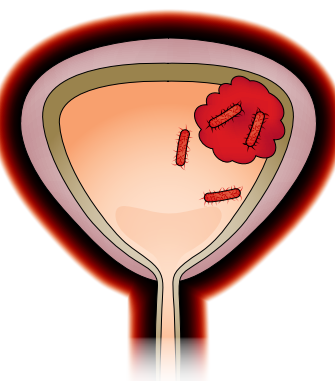

\begin{tabular}{|l|l|}
\hline $\begin{array}{l}\text { Laboratory } \\
\text { parameters }\end{array}$ & $\begin{array}{l}\text { Bacteriuria, haematuria, pyuria and elevated urine } \\
\text { cytokines. }\end{array}$ \\
\hline Prevalence & $\begin{array}{l}\text { Overall, } \sim 10 \% \text { of women have yearly episodes, }>40 \% \\
\text { of women have one episode during their lifetime. } \\
\text { Recurrences are common and often occur in clusters. }\end{array}$ \\
\hline $\begin{array}{l}\text { Current } \\
\text { treatment } \\
\text { protocol }\end{array}$ & $\begin{array}{l}\text { Acute antibiotic treatment, 3-7 days of narrow- } \\
\text { spectrum antibiotics as a first-line therapy, few } \\
\text { effective new treatment options. }\end{array}$ \\
\hline
\end{tabular}

\section{c Asymptomatic bacteriuria}

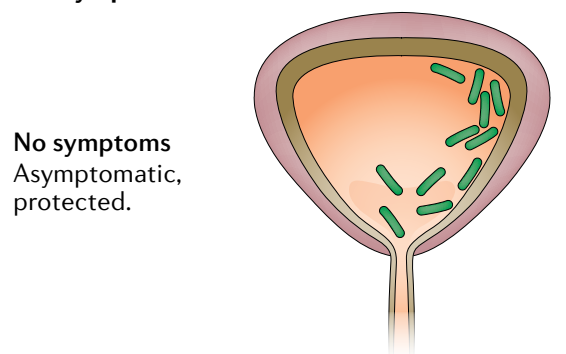

\begin{tabular}{|l|l|}
\hline $\begin{array}{l}\text { Laboratory } \\
\text { parameters }\end{array}$ & $\begin{array}{l}\text { Bacteriuria }\left(>10^{5} \mathrm{cfu} / \mathrm{ml} \text { of urine) without symptoms. }\right. \\
\text { A moderate local inflammatory response might occur. }\end{array}$ \\
\hline Prevalence & $\begin{array}{l}\text { Overall, } \sim 1 \% \text { in girls, } 1-5 \% \text { of premenopausal women, } \\
2-10 \% \text { in pregnant women, } ~ 20 \% \text { in healthy } \\
\text { individuals }>70 \text { years of age. }\end{array}$ \\
\hline $\begin{array}{l}\text { Current } \\
\text { treatment } \\
\text { protocol }\end{array}$ & $\begin{array}{l}\text { Recommended to leave untreated in the absence of } \\
\text { risk factors. }\end{array}$ \\
\hline
\end{tabular}

Fig. 2 | Symptomatic infections and asymptomatic bacteriuria. a | Acute pyelonephritis is a severe bacterial infection localized to the kidneys with systemic involvement and considerable mortality. Spread of bacteria to the blood stream (urosepsis), occurs in about $30 \%$ of adults ${ }^{20-23}$. Infection gives rise to an innate immune response and local inflammation in the kidneys, as well as systemic spread of pro-inflammatory mediators, which cause fever, general malaise and activate the acute phase response. $\mathbf{b} \mid$ Acute cystitis is an infection of the urinary bladder and lower urinary tract. An often potent, inflammatory response causes bladder oedema, hyperaemia and pyuria, and patients experience pain, dysuria and increased frequency. c | However, bacteriuria is not always accompanied by inflammation and disease. In asymptomatic bacteriuria, the urinary tract is colonized by bacteria without evidence of disease. This condition is defined by repeated positive urine cultures in an asymptomatic patient. CRP, C-reactive protein. 
uropathogenic E. coli develop an ABU-like state, owing to reduced inflammation and bacterial clearance $e^{9,32,60,80}$. Consistent with these studies, $C d 14^{-/}$mice show increased bacterial numbers in urine and bladder tissues compared with wild-type mice, suggesting that like Tlr $4^{-/-}$mice, $C d 14^{-/-}$mice could develop $\mathrm{ABU}^{62}$.

Clinical studies have provided evidence of TLR4 attenuation in patients with ABU. TLR4 expression was reduced compared with age-matched healthy participants, and this phenotype was attributed to attenuating TLR4 promoter polymorphisms not observed in symptomatic $\mathrm{UTI}^{58,81}$. The identified promoter polymorphisms were shown to reduce TLR 4 expression in reporter assays and were further associated with reduced IL-8, IL-6 and neutrophil responses in patients inoculated with E. coli $83972\left(\right.$ REFS $\left.^{59,82,83}\right)$. However, genetic variants affecting TRIF, TRAM or MYD88 expression were not detected in these patients, indicating that the receptor rather than the adaptor proteins influences ABU establishment.
These results show that $\mathrm{ABU}$ strains are sophisticated, actively adapting organisms that persist in the urinary tract, especially in hosts in whom TLR4 expression is reduced. By actively suppressing host gene expression, ABU strains adapt further, potentially inhibiting destructive immune hyper-activation in the host.

\section{From ABU to APN}

An unexpected observation has suggested that an $A B U$ strain might become virulent if equipped with a single 'super-virulence factor', specifically, the papG adhesin gene $^{79}$. These findings contradict the dogma of virulence necessarily being multifactorial and suggest that a single super-virulence factor might suffice to orchestrate a molecular transition from ABU to APN in the host ${ }^{79}$.

\section{Divergent effects of fimbriae}

The observation of the potential of a single supervirulence factor was made in patients with recurrent UTIs who were inoculated with the ABU strain E. coli

\section{A Bacterial factors}

Aa Lack of virulence

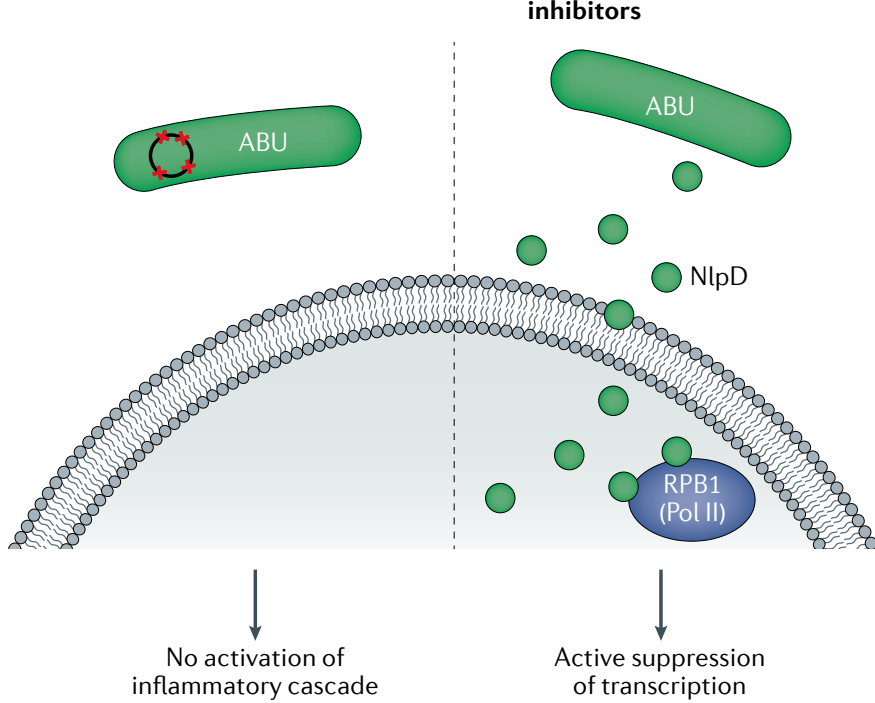

Mouse single-gene knockout associated with $\mathrm{ABU}$

\begin{tabular}{|l|l|}
\hline Tlr4 ${ }^{-/}$ & $\begin{array}{l}\text { High bacterial counts, low PMN influx, prolonged infection, } \\
\text { no symptoms of disease }\end{array}$ \\
\hline Trif ${ }^{--}$ & High bacterial counts, low PMN influx \\
\hline Myd88 $^{-/-}$ & High bacterial counts, luminal PMN aggregates \\
\hline Tram & High bacterial counts, low PMN influx \\
\hline
\end{tabular}

Fig. 3 | Molecular determinants of asymptomatic bacteriuria. Asymptomatic bacteriuria (ABU) is explained by both bacterial factors and host determinants that facilitate symbiosis. A|Bacterial factors: $A B U$ strains coexist with their hosts without triggering symptoms. Several mechanisms contribute to this effect. Aa $\mid A B U$ strains do not provoke a potent innate immune response in the host owing to a lack functional virulence genes. $\mathbf{A b} \mid A B U$ strains modify the host environment by actively inhibiting host gene expression. They secrete inhibitors of host RNA polymerase II (Pol II) such as NlpD, which targets the Pol II phosphorylation complex and inhibits gene expression, including pro-inflammatory genes. B | Host determinants: Toll-like receptor 4 (TLR4) signalling controls many aspects of the innate response to urinary tract infection. TLR4 signalling is attenuated in patients with ABU. At least
B Host determinants

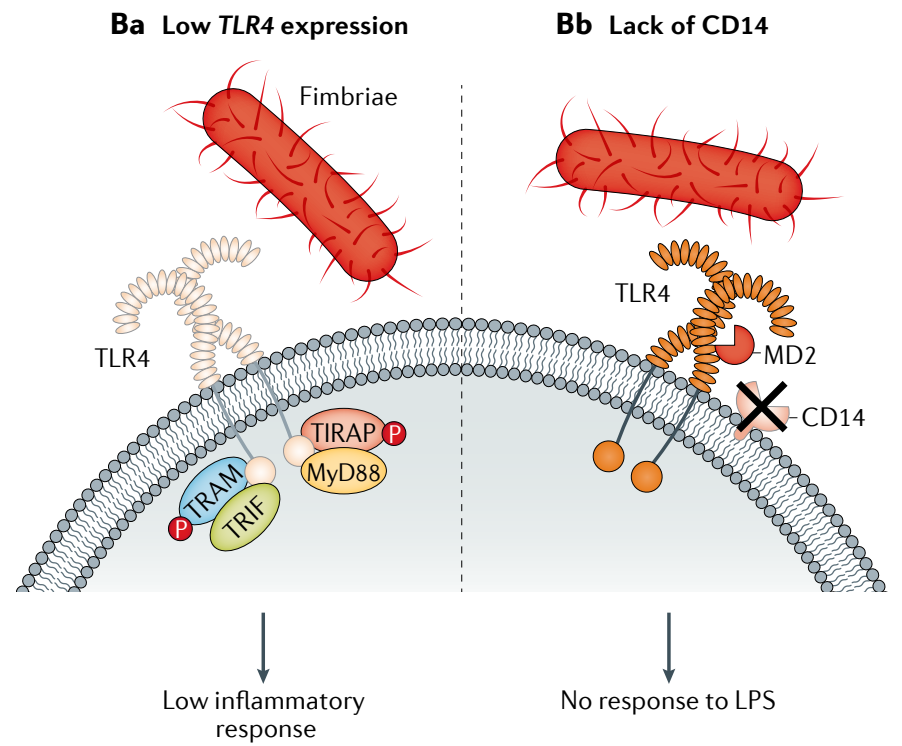

Human polymorphisms associated with $A B U$

TLR4 promoter SNPs Low promoter activity and TLR4 expression 


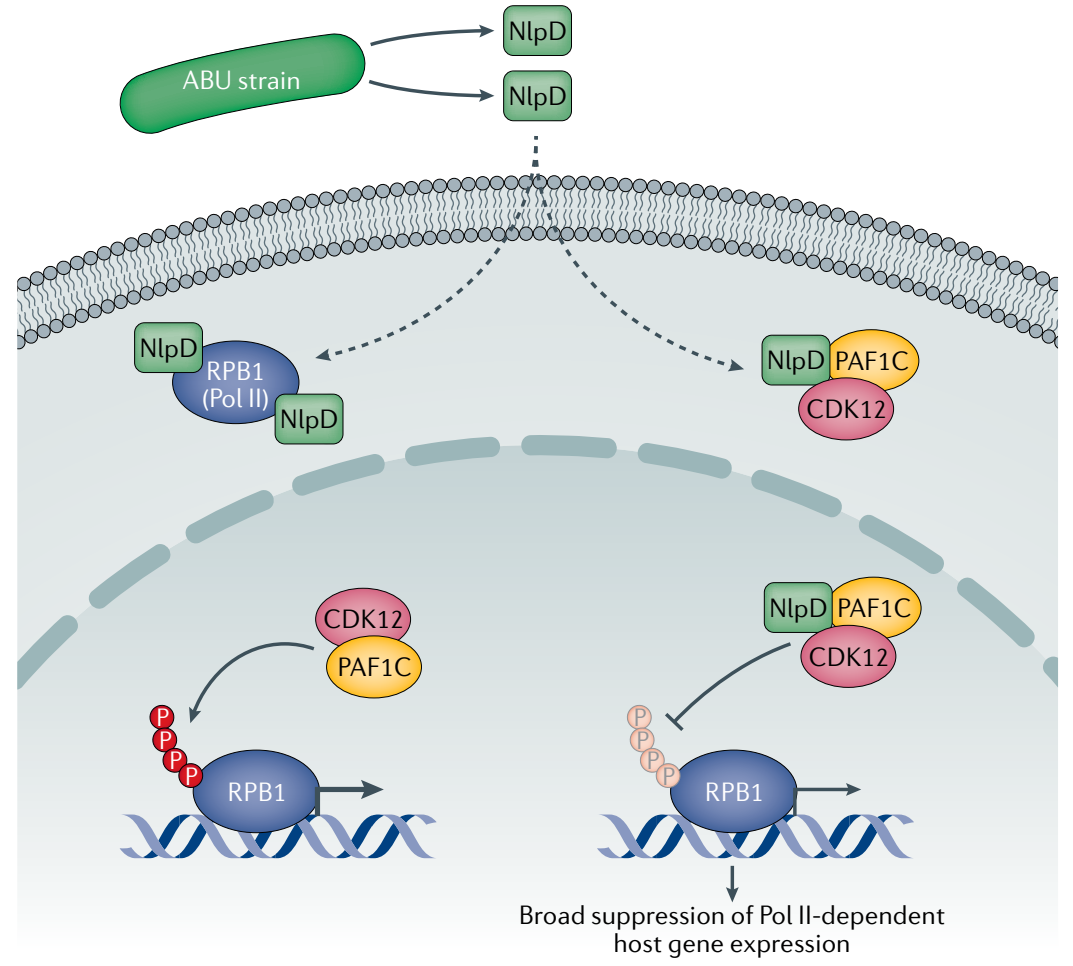

Fig. 4 | Mechanism of RNA polymerase II inhibition by asymptomatic bacteriuria strains. Asymptomatic bacteriuria (ABU) strains establish a symbiotic relationship with their host, in part by inhibiting RNA polymerase II (Pol II)-dependent gene expression. The NlpD protein, released by the bacteria, is internalized by host cells, where it targets DNA-directed RNA polymerase Il subunit RPB1/POLR2A (RPB1) and the phosphorylation complex constituent polymerase-associated factor 1 complex (PAF1C), which recruits the cyclin-dependent kinase 12 (CDK12) to the complex. As a result, Pol II phosphorylation by CDK12 is inhibited and host gene expression is suppressed. Protective effects of NlpD in mice infected with the uropathogenic Escherichia coli (UPEC) strains CFT073 or CY17 have also been associated with reduced Pol II phosphorylation. P, phosphate group.

83972, a safe and protective approach to treating UTI, especially in patients with residual urine $e^{50}$. To further develop the E. coli 83972 inoculation therapy for patient groups with increased diversity, fimbrial gene clusters that are either mutated or not expressed in E. coli 83972 have been repaired. The pap gene cluster was repaired in $E$. coli 83972 by reconstituting the papG adhesin gene, promoting bacterial adherence to the mucosal surface of the bladder and potentially enhancing the efficiency of E. coli 83972 inoculation as a therapeutic tool in patients without residual urine ${ }^{79}$. The pap gene cluster was chromosomally reconstituted using homologous recombination, replacing the mutated $p a p G$ with functional pap $G X$ genes from the uropathogenic $E$. coli (UPEC) strain E. coli CFT073 (REF. ${ }^{84}$ ). The resulting E. coli 83972pap expressed functional $P$ fimbriae, shown by $\mathrm{P}$ blood group-specific agglutination of human erythrocytes and attachment to human kidney cells. Separately, the entire fim operon from E. coli CFT073 was introduced into E. coli 83972 to repair the internal 4,253-bp fim deletion. The reconstituted E. coli 83972 fim strain expressed functional type 1 fimbriae, shown by $a$-D-methyl-mannose reversible agglutination of human and guinea pig erythrocytes and reversible adherence to human kidney cells ${ }^{79}$.
The reconstituted strains were used for human inoculation and five patients inoculated with E. coli 83972 or E. coli 83972fim on different occasions, developed $\mathrm{ABU}^{79}$. Unexpectedly, two of the patients who received E. coli 83972 pap became symptomatic. The patients were treated with antibiotics, their symptoms resolved, and the study was discontinued. The molecular basis of the symptomatic response was investigated using genome-wide transcriptomic analysis technology ${ }^{79}$ (FIG. 5). E. coli 83972pap was found to reprogramme host gene expression, including genes in the interferon pathway and the pattern receptor recognition (PRR) pathway, which were activated ${ }^{32}$. At the time of symptoms, regulated genes also included IRF7, OAS3, OAS1 and $O A S 2$, complement components, IFIH1 (which encodes MDA5), DDX58 (which encodes RIG-1), IL1B, NLRC4 (which encodes IPAF), TNF, RIPK2 (which encodes RIP2), IL6 and NOD2, several of which have been highly implicated in UTI pathogenesis. A strong IRF7 response was detected in samples taken close to the symptomatic episodes ${ }^{34,79}$, confirming observations in the mouse UTI model, in which IRF7 has been identified as a major regulator of the disease response during APN. Other identified transcriptional nodes included IRF3 and STAT1, which regulate the protective, type I interferon-dependent response ${ }^{32}$. The PapG adhesin protein was further shown to enter host cells and to regulate IRF7 expression by direct promoter binding, affecting the IRF7 transcription complex assembly, together with IRF3, MYC and IFN $\beta^{79}$ (FIG. 6). These findings provide a mechanism for how classical transcriptional regulators might contribute to the pathophysiology of APN and be the link to IRF7-driven disease ${ }^{34}$.

By contrast, the fim reconstituted strain E. coli 83972 fim was shown to attenuate host gene expression, inhibiting genes involved in RNA processing, post-transcriptional regulation and ribosome biogenesis $^{79}$ (FIG. 5). No evidence of inflammation was observed and pro-inflammatory gene sets were not significantly regulated (cut-off of $P<0.05$ compared with the pre-inoculation sample in each patient). Furthermore, effects on gene expression did not include IRF7 or IRF-dependent genes.

The results suggest that type 1 fimbriae enhance the inhibitory effects of E. coli 83972 on host gene expression by affecting the post-transcriptional environment in infected hosts (FIG. 5). The analysis also revealed moderate activation of potassium channels, ion anti-porters, voltage-gated cation channels and substrate-specific ion channels $^{79}$. Activated genes also affected neuropeptide signalling, sensory perception of pain, neurotransmitter receptors and nervous system development ${ }^{35,79}$. These gene profiles are interesting as type 1 fimbriae have been associated with acute cystitis ${ }^{85-88}$, in which ion channel activation can lead to neuropeptide activation, causing pain, urgency and frequency.

These results suggest that $P$ fimbriae highjack the transcriptional machinery of the host, creating a fimbriae-specific gene expression profile. $P$ fimbriae are expressed by $95-100 \%$ of APN isolates in patients without underlying disorders ${ }^{89}$, suggesting that expression of these adhesive ligands is essential for the 
pathogenesis of APN. Thus, loss of P fimbriae would be a first step towards virulence attenuation and adaptation to long-term persistence in the urinary tract. This possibility is supported by a high frequency of inactivating papG mutations in $\mathrm{ABU}$ isolates ${ }^{56}$. These findings suggest that virulence gene attenuation could be a new therapeutic alternative to antibiotics for treating UTI, focusing on super-virulence gene attenuation

Table 1 | Mouse single-gene knockout models

\begin{tabular}{|c|c|c|}
\hline Mouse strain & Outcome of infection & Refs \\
\hline \multicolumn{3}{|c|}{ Asymptomatic bacteriuria } \\
\hline$T l r 4^{-/-}$ & $\begin{array}{l}\text { High bacterial counts, low PMN influx, prolonged } \\
\text { infection, no symptoms of disease }\end{array}$ & 60 \\
\hline Trif $^{-/-}$ & High bacterial counts, low PMN influx & 60 \\
\hline Tram $^{-1-}$ & High bacterial counts, low PMN influx & 60 \\
\hline Myd88-/- & High bacterial counts, luminal PMN aggregates & 60 \\
\hline \multicolumn{3}{|c|}{ Cystitis, recurrent UTI } \\
\hline Nlrp3 $3^{-1-}$ & High bacterial counts, influx of leukocytes & 33 \\
\hline $\mathrm{Asc}^{-/-}$ & High bacterial counts, influx of leukocytes & 33 \\
\hline $\operatorname{Tlr} 5^{-/-}$ & $\begin{array}{l}\text { Prolonged infection and inflammation at later time } \\
\text { points }\end{array}$ & 139 \\
\hline $\operatorname{Tl} 11^{-/-}$ & High bacterial counts, influx of leukocytes & 182 \\
\hline $\operatorname{Cox} 2^{-1-}$ & High bacterial counts in bladder & 189 \\
\hline $\mathrm{Cd} 14^{-/-}$ & High bacterial counts in bladder & 241 \\
\hline$P t \times 3^{-1-}$ & $\begin{array}{l}\text { Increased susceptibility, high bacterial counts } \\
\text { in bladder and kidneys }\end{array}$ & 179 \\
\hline $1117 a^{-/-}$ & Increased susceptibility, fewer PMNs & 205 \\
\hline $\operatorname{Tcrd}^{-/-}$, Ifnb $1^{-/-}, \mid l 4^{-/-}$ & Increased susceptibility & 242 \\
\hline \multicolumn{3}{|l|}{ Acute pyelonephritis } \\
\hline $\operatorname{lrf} 3^{-/-}$ & $\begin{array}{l}\text { Severe APN, acute mortality, sepsis, high bacterial } \\
\text { counts, large renal abscesses }\end{array}$ & 32,34 \\
\hline Ifnb $1^{-/-}$ & $\begin{array}{l}\text { Severe APN, acute mortality, sepsis, high bacterial } \\
\text { counts, large renal abscesses and pathology }\end{array}$ & 32 \\
\hline $\mathrm{Cxcr2}^{-1-}$ & $\begin{array}{l}\text { Severe APN, acute mortality, sepsis, high bacterial } \\
\text { counts, large renal abscesses and pathology }\end{array}$ & $31,164,169$ \\
\hline $116^{-1-}$ & Severe APN, high bacterial counts & 156 \\
\hline $\mathrm{CAMP}^{-/-}$ & $\begin{array}{l}\text { High bacterial counts, pathology and severe } \\
\text { symptoms }\end{array}$ & 174 \\
\hline $\mathrm{Thp}^{-/-}$ & High bacterial counts & 188 \\
\hline Nod2 $2^{-1-}$ & Kidney abscesses & 243 \\
\hline Thrombomodulin ${ }^{-/-}$ & Elevated bacterial loads & 244 \\
\hline$P 2 \times 7^{-/-}, P 2 \times 4^{-/-}$ & Increased sensitivity to sepsis & 245 \\
\hline \multicolumn{3}{|c|}{ Resistant phenotype } \\
\hline $\operatorname{lrf} 7^{-/-}$ & Highly resistant to UTI & 34 \\
\hline $111 b^{-/-}$ & Highly resistant to UTI & 33,80 \\
\hline Atg16l1 $1 /-$ & Increased bladder clearance, protection & 246 \\
\hline C5ar1 $1^{-/-}$ & Protected against kidney infection & 247 \\
\hline Nos2 $2^{-1-}, 1110^{-/-}$ & No increased susceptibility & 242 \\
\hline S100a9-/- & Intact response, clearance & 248 \\
\hline$T l r 2^{-/-}$ & Intact response, clearance & 60 \\
\hline Casp1 $1^{-/-}, \mathrm{Mmp7}^{-/-}$ & Intact response, clearance & 33 \\
\hline
\end{tabular}

APN, acute pyelonephritis; PMN, polymorphonuclear neutrophil; UTI, urinary tract infection. rather than indiscriminate removal of the bacteria. The results further suggest that $\mathrm{ABU}$ strains without functional $\mathrm{P}$ fimbriae would be preferred for use for human inoculation.

These findings further illustrate the remarkably divergent effects of $\mathrm{P}$ fimbriae and type 1 fimbriae, in infected hosts. Specifically, P fimbriae act as agonists of IRF7 and of downstream genes associated with APN. The response to E. coli $83972 \mathrm{fim}$ suggests novel cellular targets that need further study.

\section{Acute pyelonephritis}

APN is a worst-case scenario and the opposite of ABU. UPEC strains attack the renal pelvic mucosa and can invade the renal parenchyma and reach the blood stream, causing urosepsis ${ }^{90-92}$. Systemic involvement gives rise to fever $\left(>38^{\circ} \mathrm{C}\right)$, elevated $\mathrm{C}$-reactive protein (CRP) in blood and general malaise, owing to the spread of innate immune mediators, such as IL-6, from the site of infection ${ }^{93,94}$ (FIG. 2). In addition to the acute morbidity and mortality associated with APN, chronic tissue damage is common and renal tissue damage can cause focal scar formation, growth retardation and loss of function ${ }^{25,95-97}$.

\section{Triggering the host response in APN}

APN is caused by excessive innate immune activation in infected kidneys ${ }^{6}$, which is controlled by TLR interactions, and by the activation state of downstream transcriptional switches, which regulate cytokine and chemokine cascades, the recruitment and activation of inflammatory cells and the effector functions required to clear bacteria from infected tissue sites ${ }^{98}$. Early studies showed that UPEC strains activate epithelial IL-6, IL-1, TNF and IL-8 production, providing a link between microbial recognition by epithelial cells and neutrophil-dependent inflammation ${ }^{93,94}$. Subsequent studies and proteomic screens have extended the repertoire of inflammatory mediators and responding host cells to include nerve cells, mast cells, lymphocytes and NK cells, among others ${ }^{99}$. The mechanism of neutrophil recruitment involves specific chemokines, such as CXCL8, KC and MCP1, and the CXCR1 receptor is required for neutrophil activation, bacterial clearance and neutrophil exit from infected tissues into the urine, a prerequisite for avoiding tissue damage ${ }^{31}$. Extended gene expression profiling of infected cells and tissues has been used to characterize key transcriptional regulators of the innate immune response in the kidneys, including IRF3 and IRF7, MYC and NF- $\kappa \mathrm{B}$, and gene deletion studies in mice have shown IRF3, IRF7 and CXCR1 to be disease regulators ${ }^{31,32,34}$. Innate immune hyper-activation is rapid and pronounced in $I r f 3^{-/-}$mice, owing to Irf7 hyper-activation and a gene network comprising IL-6, TLR4, FOS and STAT3 (REF. ${ }^{34}$ ) (FIG. 5).

\section{Virulence determinants in APN strains}

APN strains are efficient pathogens defined by co-ordinately regulated virulence genes ${ }^{100,101}$, which engage in multiple parallel mechanisms of tissue attack $^{94,102,103}$. Efficient bacterial adherence characterizes the disease isolates ${ }^{63}$, providing a mechanism for 


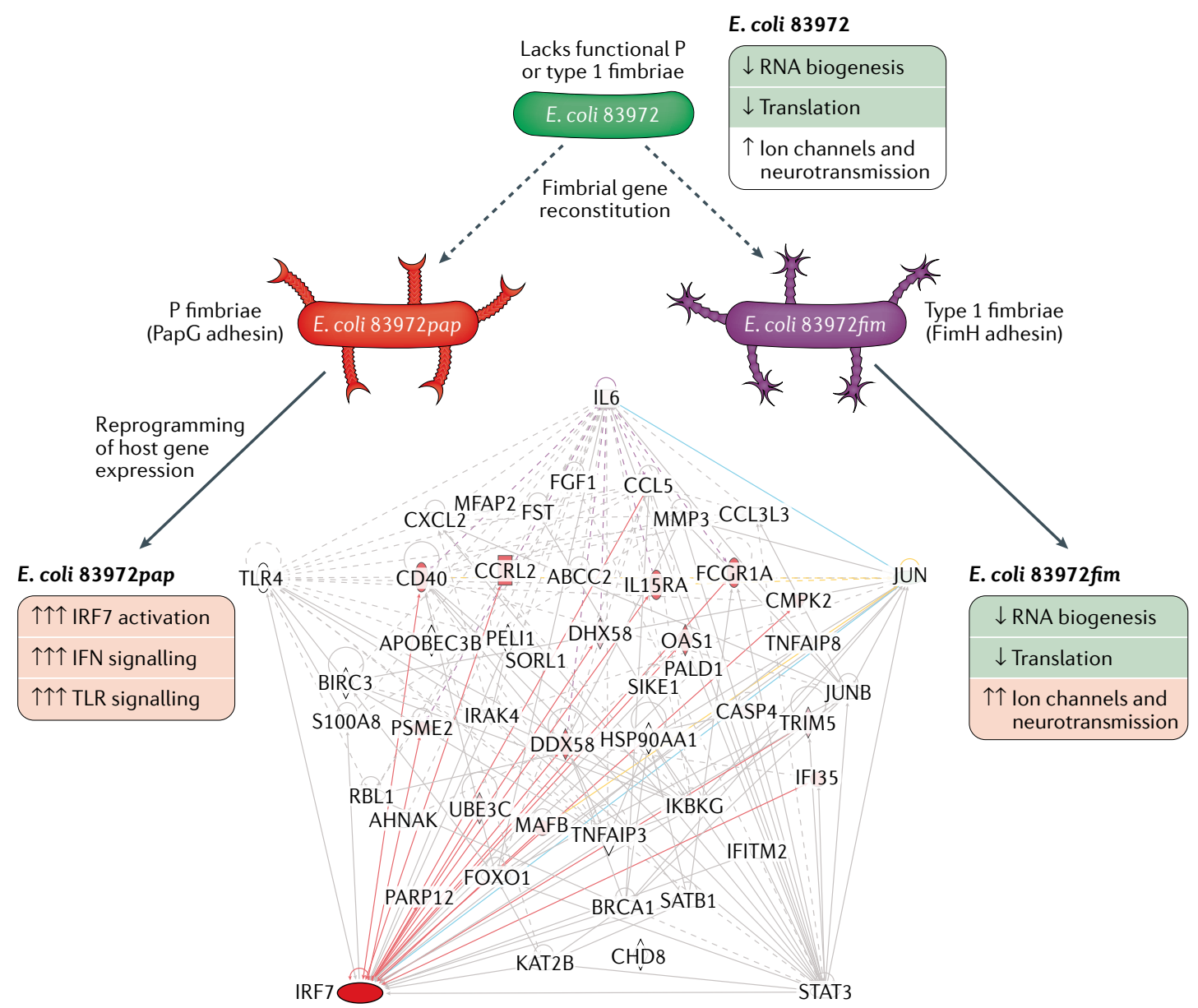

Fig. 5 | Transcriptional regulation by fimbriated bacteria in infected hosts. Human inoculation studies have been performed to prevent recurrent urinary tract infection in patients requiring alternative treatments against recurrences. The asymptomatic bacteriuria strain Escherichia coli 83972, which is attenuated for virulence, has been used successfully and protection has been demonstrated in placebo-controlled studies ${ }^{49-52}$. To extend the therapeutic use, fimbriae expression was reconstituted in E. coli 83972 and E. coli 83972pap (P fimbriated), E. coli 83972fim (type 1 fimbriated) or E. coli 83972 wild type were used to inoculate the patients ${ }^{79}$. Gene expression analysis of patient samples showed that the $P$ fimbriated strain reprogrammed host gene expression, activating interferon and pattern recognition signalling pathways. Disease symptoms in two of the inoculated patients were accompanied by interferon regulatory factor 7 (IRF7) activation. By contrast, the type 1 fimbriated strain did not induce symptoms but inhibited RNA biogenesis and translation. Furthermore, E. coli 83972fim activated the expression of ion channels and neuropeptide-related genes in the host. TLR, Toll-like receptor.

the pathogen to engage with the host. Extensive studies have subsequently defined a number of bacterial virulence factors ${ }^{104,105}$ and increased understanding of virulence and the niche-specific adaptation to the urinary tract environment ${ }^{106}$. The presence of large chromosomal islands distinguishes pathogenic strains from non-pathogenic E. coli K-12 strains ${ }^{107}$. PAI-CFT073-serU and PAI-CFT073-pheU, harbouring $\mathrm{P}$ fimbriae and TcpC genes, are more strongly associated with APN and urosepsis than with $\mathrm{ABU}$ or cystitis ${ }^{108}$. PAI deletions reduce virulence ${ }^{109}$, despite fully functional virulence genes on other PAIs, suggesting a regulatory role ${ }^{110}$.

Adhesins and other virulence factors, expressed by uropathogenic E. coli. The interplay between fimbrial adhesins and host receptors provides molecular keys to innate immune activation and tissue access of additional virulence factors $\mathrm{s}^{60,111,112}$. P fimbriae provide a direct disease-associated mechanism of tissue attack, by enhancing adherence, activating Tlr4 signalling and activating the expression of the APN-associated transcription factor IRF7 (REFS ${ }^{34,79}$ ) (FIG. 6). P-fimbriated E. coli activate ceramide release by binding to receptor motifs present in the extracellular oligosaccharide domains of glycosphingolipid receptors, overriding the mucosal inertia to LPS ${ }^{113-115}$. Downstream signalling involves the TLR4 adaptor proteins TIR domaincontaining adapter molecule 2 or TICAM2 (TRAM) and TIR domain-containing adapter molecule 1 or TICAM1 (TRIF) (FIG. 6), the phosphorylation of mitogen-activated protein (MAP) kinases, phospholipase $\mathrm{C} \gamma$, p38, activating JUN N-terminal kinases (JNKs), CREB (cyclic AMP response element-binding) and IRF-dependent and AP-1-dependent transcription of cytokines and chemokines, as well as type I interferons including IFN $\beta^{32,116}$. P fimbriae are expressed by up to $100 \%$ of 


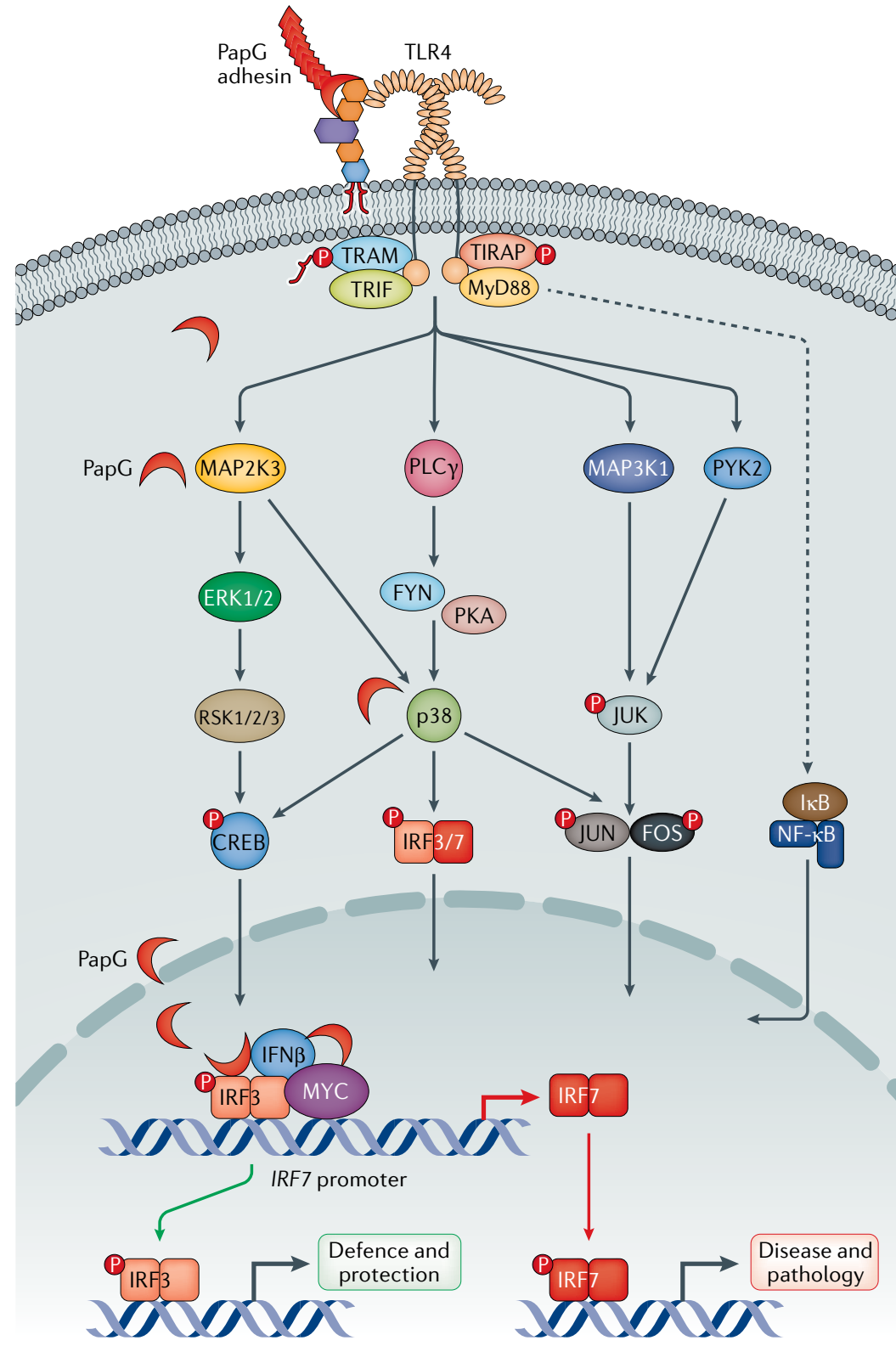

Mouse single-gene knockout

\begin{tabular}{|l|l|}
\hline $\operatorname{lrf} 3^{-/-}$ & $\begin{array}{l}\text { Acute mortality, sepsis, high } \\
\text { bacterial counts, large renal } \\
\text { abscesses and pathology }\end{array}$ \\
\hline $\operatorname{lrf7^{-/-}}$ & Highly resistant to UTI \\
\hline $\operatorname{Ifnb} 1^{-/-}$ & $\begin{array}{l}\text { Acute mortality, sepsis, high } \\
\text { bacterial counts, large renal } \\
\text { abscesses and pathology }\end{array}$ \\
\hline
\end{tabular}

Human polymorphisms

\begin{tabular}{|l|l|l|}
\hline $\begin{array}{l}\text { IRF3 promoter } \\
\text { SNPs }\end{array}$ & $\begin{array}{l}\text { Low promoter } \\
\text { activity }\end{array}$ & APN \\
\hline IRF7 promoter SNP & Low expression & ABU \\
\hline
\end{tabular}

$\mathrm{APN}$ and urosepsis strains but are rare in ABU strains, unlike type 1 fimbriae ${ }^{89,104}$.

Other virulence-associated adhesins in APN strains include the Dr adhesin family of fimbrial and afimbrial components and $\mathrm{S}$ fimbriae that bind to the mucosa and type IV collagen on basement membranes ${ }^{117,118}$, facilitating invasion ${ }^{119}$. Type 1 fimbriae contribute to the pathogenesis of APN in the mouse UTI model but are not directly associated with virulence in epidemiological studies, suggesting a different role ${ }^{120,121}$.
Fig. 6 | TLR4 signalling and transcriptional control of the innate immune response in acute pyelonephritis. P fimbriated uropathogenic Escherichia coli (UPEC) strains activate a Toll-like receptor 4 (TLR4) signalling cascade by phosphorylation of the TLR4 adaptor proteins (TRIF, TRAM, MyD88 and TIRAP). The PapG adhesin binds to glycosphingolipid receptors, releasing ceramide, which activates TLR4 signalling. Downstream MAP kinase signalling converges on $\mathrm{p} 38$, which controls the phosphorylation and activation of interferon regulatory factor 3 (IRF3), as well as NF- $\mathrm{kB}$ and activator protein 1 (AP-1); a heterodimer of FOS and JUN. IRF7 activation requires de novo synthesis followed by phosphorylation. IRF3 and IRF7 control disease severity by regulating different aspects of the antimicrobial defence and the inflammatory response of mice infected with UPEC strains. IRF3 is essential for the protective response and mice lacking IRF3 (Irf3 $3^{-/-}$mice) develop severe acute infection with sepsis and mortality, followed by renal damage ${ }^{32,34}$. Downstream mediators such as IFN $\beta$ are of crucial importance for the Irf3-dependent defence to occur and Ifnb $1^{-/-}$mice develop a similar disease phenotype when infected with UPEC strains $^{32}$. By contrast, IRF7 drives disease and tissue pathology and mice lacking IRF7 (Irf7 ${ }^{-/-}$mice) are protected from acute pyelonephritis ${ }^{34}$. In addition, PapG is internalized and engages the IRF7 promoter complex together with IRF3, IFN $\beta$ and MYC. The PapG adhesin acts a transcriptional IRF7 agonist, affecting the repertoire of genes expressed during acute pyelonephritis. Human promoter polymorphisms predicted to affect the susceptibility to acute pyelonephritis by reducing the expression of IRF3 have been detected in about $70 \%$ of patients with acute pyelonephritis ${ }^{32}$. Attenuating IRF7 polymorphisms have been detected in asymptomatic bacteriuria ${ }^{34}$. $\mathrm{ABU}$, asymptomatic bacteriuria; APN, acute pyelonephritis; CREB, cyclic AMP response element-binding; $\mathrm{P}$, phosphate group; SNP, single-nucleotide polymorphism; UTI, urinary tract infection. Adapted from REF. ${ }^{6}$, Springer Nature Limited, and from REF. ${ }^{79}$, CC BY 4.0 (https:// creativecommons.org/licenses/by/4.0/).

Endotoxins and exotoxins are important for bacterial tissue attack and act either directly as cytotoxic agents or indirectly by triggering inflammation and tissue damage ${ }^{122}$. Uropathogenic strains produce haemolysin, which is toxic to kidney cells and causes urothelial damage and haematuria ${ }^{123,124}$. The precise mechanism of action of the E. coli haemolysin and the pore formation in human cells is still debated, as most studies of haemolysin have been performed using $\alpha$-haemolysin isolated from other bacterial species such as Staphylococcus aureus $^{125,126}$. Currently, two theories exist that suggest that haemolysin either directly engages the lipid bilayer of the plasma membrane or the membrane-bound protein ADAM10, which then further facilitates membrane access $^{127}$. Furthermore, the cytotoxic necrotizing factor 1 (CNF1) and Rho-GTPase-activating toxins secreted by UPEC strains are associated with adherence and invasion, inducing actin cytoskeleton reorganization in host cells and initiating apoptosis ${ }^{128}$.

Moreover, bacterial iron acquisition systems are activated in the urinary tract ${ }^{129}$ and several siderophores expressed by UPEC strains are essential in vivo, where they contribute to bacterial fitness during infection ${ }^{130-134}$. The siderophore aerobactin, shows a 
virulence-associated expression pattern and promotes persistence in the urinary tract ${ }^{135}$. Lipocalin 2 binds and sequesters enterobactin, a siderophore implicated in iron acquisition ${ }^{133}$. UPEC strains can also escape the host defence by glycosylation of enterobactin, and the product known as salmochelin is not recognized by its ligand lipocalin 2 (REFS ${ }^{133,134}$ ).

Flagella, capsular polysaccharides and immune evasion proteins all contribute to the disease process by supporting the ascent of bacteria to the upper urinary tract $^{136}$ and conferring resistance to antibacterial effectors of inflammation. Flagella are essential for bacterial motility and to enable bacteria to ascend from the infected bladder into the renal pelvis. Flagella have been shown to engage TLR5 and activate innate immune signalling ${ }^{137}$. The uptake of UPEC strains by renal cells is supported by opsonization of bacteria with the complement component $\mathrm{C} 3$ and the presence of epithelial cell membrane C3 receptors ${ }^{138}$.

Studies of individual virulence factors clearly support their effects in cellular systems and animal models, but further studies are required to evaluate their specific contributions to disease alone or in combination.

TIR domain proteins in UPEC strains suppress the innate immune response to virulent strains. Given the central role of the TLRs in the host defence $e^{60,77,139,140}$, unsurprisingly, bacteria have evolved mechanisms to specifically interfere with TLR-mediated immune responses. TIR domain homologues have been detected in plants, mediating pathogen detection and defence responses ${ }^{141}$, and in bacteria, viruses and archaea, illustrating the importance of this protein family ${ }^{142-144}$. The ancestral prokaryotic TIR domains have been found to act as NADase enzymes, cleaving $\mathrm{NAD}^{+}$into nicotinamide and ADPribose, therefore regulating oxidoreduction processes and cellular metabolism ${ }^{145}$. In bacteria, TIR-containing proteins (Tcps) suppress innate immunity in mice with $\mathrm{UTI}^{143}$. A TIR homologue is present in the genome of UPEC CFT073 and the bacteria secrete inhibitory TIR domain homologues that interfere with TLR signalling by competitive binding to MyD88 in vitro ${ }^{80,144}$. TcpC is most commonly expressed in virulent UPEC strains and has been shown to promote bacterial survival and kidney pathology in a mouse UTI model ${ }^{143}$. These observations suggest that pathogens are capable of directly modifying the TLR-dependent host defence by using TIR domain homologues.

UPEC strains produce inhibitors of the MYC oncogene. The bacteria-host interaction model helps in the discovery of molecules with biologically relevant effects in diseases other than UTI. In addition to producing molecules that directly affect virulence, UPEC strains were shown to inhibit and degrade the MYC oncogene protein ${ }^{146}$. Cancer cells are fast growing, outcompete non-malignant cells and spread to distant sites, where they cause metastasis ${ }^{147}$. Understanding what makes cancer cells so efficient and threatening is crucially important, and stopping them has always been the goal of cancer research. Early studies identified oncogenes; genes that normally control cell growth but when mutated can be responsible for oncogenic transformation and explain the competitive advantage of cancer cells ${ }^{148}$.

The pleiotropic transcription factor MYC has been named 'the quintessential oncogene' and is hyperactive in the majority of human cancers ${ }^{149}$. Targeting MYC is, therefore, highly desirable. Myc inhibition clearly arrests cancer progression and restores tissue integrity in transgenic mouse models ${ }^{149,150}$ and a vast number of technologies have been applied in attempts to target MYC and its different co-factors in cancer cells. Still, finding MYC inhibitors for therapeutic use has been problematic and MYC itself has long been viewed as undruggable ${ }^{151}$.

Surprisingly, UPEC strains deplete MYC protein from infected cells and tissues as a result of accelerated MYC protein degradation and attenuated MYC expression ${ }^{146}$. This bacterial strategy was translated to cancer therapy, demonstrating that Lon protease treatment is efficacious in slowing cancer progression and increasing survival ${ }^{146}$. The bacterial Lon protease is shown to rapidly degrade MYC without affecting MAX and other upstream regulators such as AKT, CDK9 or CPEB1, suggesting a high degree of specificity for MYC ${ }^{146}$.

The Lon protease is a conserved, ATP-dependent serine protease that maintains homeostasis in prokaryotes by processing short-lived regulatory protein $\mathbf{s}^{152}$. The Lon protease targets MYC in a variety of cancer cells ${ }^{146}$, including Burkitt lymphoma cells, in which MYC was first discovered ${ }^{153}$. Gene expression profiles in Lon-treated tissues showed a strong inhibitory effect on cancer-related genes, but no major effects on other gene categories, also supporting the potential of this therapeutic approach ${ }^{146}$.

These results suggest that bacteria have evolved strategies to control MYC tissue levels in the host. As MYC drives renal development ${ }^{154}$, and APN is a substantial cause of renal growth retardation ${ }^{155}$, MYC overexpression might have evolved to protect local host environments against detrimental effects of pathogenic bacteria. Speculatively, by inhibiting mucosal MYC expression bacteria might inadvertently provide a defence against oncogenic transformation.

\section{Genetic control of APN susceptibility}

Infections constitute a major evolutionary driving force, selecting resistance traits in infected hosts and bacterial genome alterations that enhance persistence. UTIs are an excellent example, as the most severe infections cause considerable mortality and impaired renal health, and, in women specifically, reduced fertility and premature delivery, starting from childhood. Host susceptibility is now being associated with inherited genetic traits and bacteria shown to evolve by loss of virulence, facilitating symbiosis and long-term persistence.

Genes that control immune activation and essential effector functions in APN have been identified using cellular infection models, animal models and clinical studies $^{31,32,34,156-158}$. Specific genes have been shown to control APN severity by affecting initial disease activation, transcriptional regulators of inflammatory cascades, cellular antibacterial effector functions and mechanisms of tissue repair ${ }^{32,34}$ (FIC. 6; TABLE 2). Further 
Table 2 | Gene-association studies in patients

\begin{tabular}{|c|c|c|c|}
\hline Genetic variant & Biological effect & Disease association & Refs \\
\hline TLR4 promoter SNPs & $\begin{array}{l}\text { Reduced promoter activity, } \\
\text { low TLR4 expression }\end{array}$ & $\mathrm{ABU}$ & 58,249 \\
\hline TLR2 coding region SNP & NR & $\mathrm{ABU}$ and recurrent UTI & 250 \\
\hline $\begin{array}{l}\text { TLR1, TLR2, TLR4, } \\
\text { CXCR1, CXCR2 SNPs }\end{array}$ & NR & $\mathrm{ABU}$ & 81 \\
\hline IRF7 promoter SNP & Low IRF7 expression & $\mathrm{ABU}$ & 34 \\
\hline CXCR1 intronic SNP & $\begin{array}{l}\text { Reduced promoter activity, } \\
\text { low CXCR1 expression }\end{array}$ & APN & 157,171 \\
\hline CXCR1 3' UTR SNP & $\begin{array}{l}\text { Increased 3'-mRNA } \\
\text { processing }\end{array}$ & APN & $\begin{array}{r}157,171, \\
251\end{array}$ \\
\hline IRF3 promoter SNPs & Low promoter activity & APN & 32 \\
\hline $\begin{array}{l}\text { CXCL8 promoter and } \\
\text { 3' UTR SNP }\end{array}$ & NR & APN & $\begin{array}{r}158, \\
251-254\end{array}$ \\
\hline CCL5 promoter SNP & NR & APN & 181 \\
\hline IL10 promoter SNP & NR & Recurrent APN & 180 \\
\hline NLRP3 intronic SNP & NR & $\begin{array}{l}\text { Negative association } \\
\text { with APN }\end{array}$ & 255 \\
\hline $\begin{array}{l}\text { LTA coding region, TNF } \\
\text { promoter SNP }\end{array}$ & NR & Recurrent UTI & 256 \\
\hline $\begin{array}{l}\text { HSPA1B coding region } \\
\text { SNP }\end{array}$ & NR & Recurrent UTI & 257 \\
\hline $\begin{array}{l}\text { TLR1, TLR4, TLR5 coding } \\
\text { region SNP }\end{array}$ & NR & Recurrent UTI & 83 \\
\hline DEFA1A3 copy number & Low copy number & Recurrent UTI & 258 \\
\hline $\begin{array}{l}\text { TGFB1, VEGFA } \\
\text { promoter SNP }\end{array}$ & NR & UTI & 259 \\
\hline TLR4 coding region SNP & $\begin{array}{l}\text { Low monocyte and/or } \\
\text { neutrophil expression }\end{array}$ & UTI & $\begin{array}{r}257, \\
260-263\end{array}$ \\
\hline PTX3 intronic SNP & NR & UTI & 179 \\
\hline $\begin{array}{l}\text { VDR (vitamin D } \\
\text { receptor) coding region } \\
\text { and intronic SNP }\end{array}$ & NR & UTI susceptibility & 264 \\
\hline $\begin{array}{l}\text { DNA copy number } \\
\text { variations }\end{array}$ & $\begin{array}{l}\text { Enrichment in } \\
\text { innate immunity and } \\
\text { development genes }\end{array}$ & $\begin{array}{l}\text { UTI susceptibility in } \\
\text { patients with VUR }\end{array}$ & 97 \\
\hline
\end{tabular}

$\mathrm{ABU}$, asymptomatic bacteriuria; APN, acute pyelonephritis; NR, not reported; SNP, single-nucleotide polymorphism; TLR4, Toll-like receptor 4; UTI, urinary tract infection; UTR, untranslated region; VUR, vesicoureteral reflux.

evidence that APN susceptibility is genetically controlled was obtained in a three-generation family study. Inheritance of APN susceptibility was documented as an increase in APN frequency in both male and female children from families diagnosed with APN compared with children from families without UTI ${ }^{157}$. Cystitis morbidity was not inherited in these families, supporting the notion that different mechanisms control the susceptibility to APN and cystitis ${ }^{6,29}$ (TABLE 2).

Genetic control of transcriptional regulation. Gene knockout studies have been used to identify key activation steps of the innate immune response to infection. Inactivating TLR4-tir domain mutations or Tlr4 deletions inhibit innate immune activation in mice, resulting in a phenotype that resembles $\mathrm{ABU}^{9,60,80}$. Signalling cascades downstream of TLR4 converge on specific transcription factors (including IRF3, IRF7, AP1,
NF- $\kappa$ B) and their role as regulators of UTI severity has been evaluated using gene knockout technology and in clinical studies $^{32,34}$ (TABLE 1; FIG. 6). The closely related transcription factors IRF3 and IRF7 form heterodimers that regulate the activation of type I interferons and interferon-dependent genes, especially during viral infections ${ }^{159,160}$. However, in APN, these transcription factors have opposite functions. After UPEC infection, mice lacking the transcription factor Irf3 develop severe disease, accompanied by urosepsis and massive renal abscess formation $^{32}$. IFN $\beta$ is activated downstream of IRF3, and Ifnb $1^{-1-}$ mice showed a similar phenotype to $\mathrm{Irf3}^{-/-}$mice, in the same infection model.

By contrast, Irf $7^{-/-}$mice were protected from acute renal inflammation and showed no evidence of kidney pathology ${ }^{34}$, suggesting that IRF7 might drive kidney pathology ${ }^{34,79}$. IRF7-dependent gene networks were strongly upregulated in $\mathrm{Irf3} 3^{-/}$mice infected with the UPEC strain CFT073, including an Irf7-dependent gene network comprising Stat3, Tlr4 and Il6 and downstream genes involved in the acute phase response. Binding of IRF7 to promoter DNA fragments (OAS1, CCL5 and INFB1) was demonstrated, confirming the role of IRF7 as a transcriptional regulator. IRF7 was further identified as an important transcriptional mediator during group B streptococcus-induced UTI in mice, suggesting a role during infections with Gram-positive pathogens as well ${ }^{161}$.

The human relevance of these findings was supported by the detection of an IRF3 promoter sequence variants in two APN-prone patient populations ${ }^{32}$. The homozygous $\mathrm{A} / \mathrm{A}-\mathrm{C} / \mathrm{C}$ genotype (nucleotide positions -925 and -776 ) was prevalent in patients prone to APN (79\%), whereas the co-segregating heterozygous SNPs were more common in patients with $\mathrm{ABU}(69 \%)$. The APN haplotype was shown to decrease IRF3 expression in reporter assays, suggesting that IRF3 needs to be fully functional to avoid $\mathrm{APN}^{32}$.

The protective phenotype in $\mathrm{Irf}^{-/ /}$mice and overactivation of $\operatorname{Irf} 7$ in disease-prone $\operatorname{Irf3}^{-/-}$mice identified IRF7 as a potential therapeutic target. Support for this hypothesis was obtained using an siRNA-based strategy of Irf7 inhibition ${ }^{34}$. SiRNA treatment of $\mathrm{Irf3}^{-1-}$ mice infected with the UPEC strain CFT073 was shown to inhibit the excessive and destructive innate immune response and to improve bacterial clearance, resulting in resolution of infection by day 7. siRNA therapy compared favourably with antibiotic treatment (cefotaxime treatment, $100 \mathrm{mg} / \mathrm{kg})^{34}$ and Irf7 siRNA treatment was able to significantly reduce the disease score, including the number of kidney abscesses, by $95 \%$ compared with untreated mice $(P<0.01)$.

Prospective studies of genetic predisposition in childhood. The extent of genetic predisposition to APN and renal scarring has been investigated in two population-based studies. Children with a first febrile UTI episode were investigated and renal involvement was defined using dimercaptosuccinic acid (DMSA) scans. Inclusion criteria were matched, and the age range of the patients was 1 month to 2 years in population I and 3-5 months in population II. Molecular 
susceptibility determinants were identified using exome genotyping, and effects of infection and host genotype on gene expression were analysed in detail. According to preliminary findings, APN is a disease with a strong genetic component, affecting acute renal involvement and disease severity (C.S., unpublished work).

Genetic determinants of neutrophil infiltration and pathology. APN is characterized by excessive neutrophil recruitment, neutrophil accumulation and inefficient bacterial clearance from infected kidneys ${ }^{162}$. Early studies detected a rapid TLR4-dependent urine neutrophil response in the mouse model of UTI and the IL- 8 family of chemokines (CXCL8) was shown to be activated during APN in mice and patients ${ }^{78,163}$. The importance of neutrophils in the antimicrobial defence of the kidneys has been documented using genetic studies, antiinflammatory agents, bone-marrow transplants and functional assays ${ }^{31,164}$.

Gene knockout studies revealed that control of the neutrophil response is essential to clear the infection and maintain tissue integrity ${ }^{163,165-167}$. The defective neutrophil recruitment, in, for example, $T l r 4^{-1-}$ mice, protected the tissues from acute pathology but bacterial clearance was not achieved, creating an ABU-like state $^{60}$. Mice lacking a key receptor for the IL- 8 chemokine family (Cxcr2 $2^{--}$mice), developed severe APN with urosepsis and acute mortality. Surviving mice developed renal scarring, with pathology similar to human pyelonephritis. This outcome was explained by a neutrophil migration deficiency, resulting in neutrophil accumulation in infected kidneys owing to an inability to cross the pelvic epithelium into the urine and to scavenge and kill the bacteria ${ }^{31,168,169}$. The trapped neutrophils with their content of bacteria and debris became highly toxic for the renal parenchyma, resulting in renal scar formation. These results illustrate the importance of chemokines and their receptors for the control of neutrophil recruitment and bacterial clearance from infected kidneys ${ }^{31,164,170}$.

In patients with APN, susceptibility is accompanied by low CXCR1 expression and CXCR1 mRNA levels ${ }^{157,171}$. Patients prone to APN carry heterozygous CXCR1 polymorphisms attenuating receptor mRNA levels and protein expression. The presence of CXCR1 variants has been confirmed in several APN-prone patient groups ${ }^{158,172}$ Furthermore, SNPs affecting IL-8 expression (CXCL8) were detected in patients with renal involvement confirmed by positive DMSA scans, supporting the relevance in human UTI.

Other effector functions of the innate immune response. Antibacterial peptides from infected tissues and inflammatory cells are potent effectors of the renal defence against infection (such as $\beta$-defensins, ribonucleases and cathelicidin $)^{173-178}$. RNAse 7 and cathelicidins act by disrupting the phospholipid membranes of various microorganisms and are constitutively synthesized by the kidneys ${ }^{174,176}$. Lipocalin 2 (LCN2 or NGAL) is an antibacterial protein secreted both in the urine and systemically after Gram-negative infection, kidney injury or urosepsis. LCN2 binds the bacterial siderophore enterobactin, preventing iron transfer and sequestration by the bacteria ${ }^{133}$. The humoral pattern recognition molecule pentraxin 3 (PTX3) serves as an opsonin and promotes bacterial uptake by neutrophils ${ }^{179}$. PTX3 is polymorphic in UTI-prone children and adults ${ }^{179}$ (TABLE 2). Polymorphisms affecting IL10 were identified in APN-prone patients ${ }^{180}$ as well as SNPs in the CCL5 gene encoding the eosinophil product and $\mathrm{T}$ cell chemoattractant RANTES ${ }^{181}$. In mice, a loss-of-function mutation affecting Tlr11 increased bacterial burden and leukocyte infiltration compared with wild-type mice in a UTI model. TLR11 is strongly expressed in mice but the human TLR11 gene is defective and human relevance remains unclear ${ }^{182}$.

Taken together, these observations suggest that a combined effect of bacterial 'super virulence factors' and host susceptibility converge to cause severe disease in patients with APN. Starting from bacterial adherence and TLR4-mediated signalling, a blatant host response takes place with increased severity depending on the host genetics.

\section{Acute cystitis}

Acute cystitis is characterized by a pronounced mucosal inflammatory response in the lower urinary $\operatorname{tract}^{15}$. Patients experience frequency, dysuria and suprapubic pain, often accompanied by haematuria and pyuria ${ }^{183}$. A systemic host response is not typically seen, and unlike APN, acute cystitis is not accompanied by fever and general malaise ${ }^{184}$. However, recurrent episodes of acute cystitis are common and can become debilitating, especially in subsets of susceptible patients who develop interstitial cystitis and/or bladder pain syndrome as a result of prolonged mucosal inflammation and nerve excitation ${ }^{185,186}$.

\section{Genetic control of severity}

The molecular determinants of disease severity in acute cystitis have been unclear; however, mechanisms of innate immune hyper-activation have now been identified using a combination of cellular infection technology, animal models and clinical studies ${ }^{30,33,35}$. The results show that acute cystitis is an IL- $1 \beta$-driven, hyperinflammatory disorder of the infected urinary bladder driven by atypical IL- $1 \beta$ processing through matrix metalloproteinase 7 (MMP7) ${ }^{33}$ (FIG. 7). The results also suggest a genetic susceptibility mechanism of severe cystitis through mutations affecting $I L 1$ as well as $A S C$ and NLRP3 expression.

Pro-IL- $1 \beta$ is normally processed by the NLRP3 inflammasome, leading to transient, self-limiting inflammation in the bladders of C57BL/6 wild-type mice with an intact inflammasome. $I l 1 b^{-/-}$mice were protected and the effect was similar to that previously observed in $T l r 4^{-/-}$mice, suggesting that IL- $1 \beta$ is essential to drive the inflammatory response to bladder infection. Paradoxically, $\mathrm{Asc}^{-/-}$and $\mathrm{Nlrp}^{3^{-/-}}$mice carrying inflammasome gene deletions developed severe, progressive bladder disease with large, hyperaemic bladders, loss of bladder tissue integrity and elevated bacteria counts, accompanied by IL- $1 \beta$ hyper-activation ${ }^{33}$. An alternative mechanism of pro-IL- $1 \beta$ processing was detected in these severely ill mice, using gene expression analysis 
of bladder tissue. The metalloproteinase $M m p 7$ was transcriptionally hyperactivated (about 200 -fold) and was shown to cleave pro-IL- $1 \beta$, generating excessive amounts of active IL- $1 \beta$ in mice and human bladder cells ${ }^{187}$. ASC and/or NLRP3 were further identified as transcriptional repressors of the $M M P 7$ promoter, providing an explanation for the observed MMP7 over-activation in $\mathrm{Asc}^{-/-}$ and $N \operatorname{lrp} 3^{-/-}$mice $^{33}$.

Further experiments have indicated that $T l r 5, T h p$ and Cox2 also modify innate immunity to UTI and that
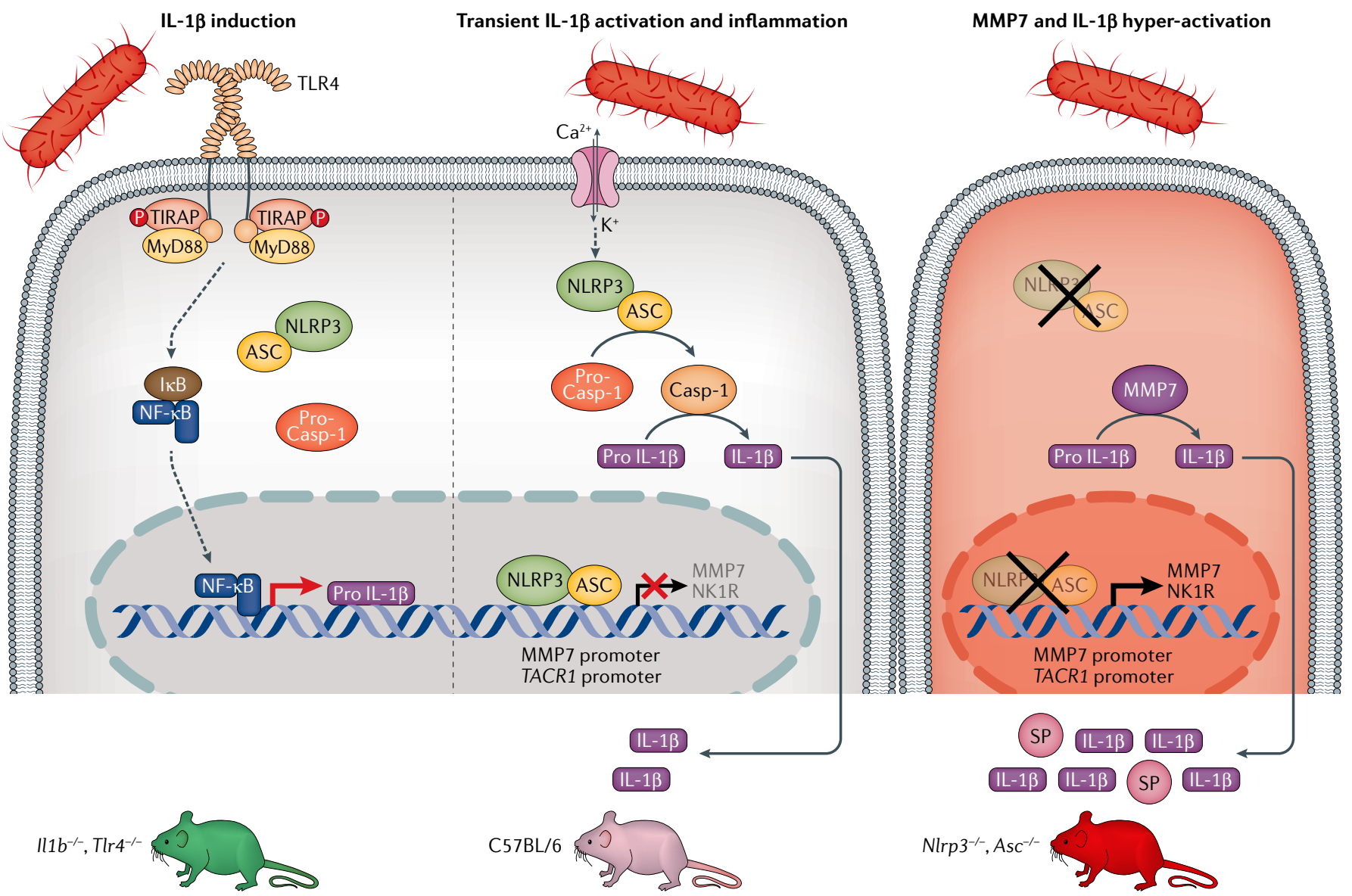

Mouse single-gene knockout protected from cystitis

\begin{tabular}{|l|l|}
\hline $111 b^{-/-}$ & $\begin{array}{l}\text { Low bacterial and neutrophil counts, } \\
\text { protection from disease }\end{array}$ \\
\hline$T l 4^{-/-}$ & $\begin{array}{l}\text { High urine bacterial counts but low } \\
\text { neutrophil counts, protection from disease }\end{array}$ \\
\hline
\end{tabular}

Wild-type mice with transient inflammation

\begin{tabular}{|l|l|}
\hline C57BL/6 & $\begin{array}{l}\text { Initial, self-limiting disease with low } \\
\text { urine bacterial and neutrophil counts } \\
\text { after } 7 \text { days }\end{array}$ \\
\hline
\end{tabular}

Mouse single-gene knockout with cystitis phenotypes

\begin{tabular}{|c|c|}
\hline$N \operatorname{lrp} 3^{-/-}$ & $\begin{array}{l}\text { High IL-1 } 1 \beta \text { release leading to severe } \\
\text { disease with tissue destruction, high } \\
\text { bacterial and neutrophil counts }\end{array}$ \\
\hline $\mathrm{Asc}^{-/-}$ & $\begin{array}{l}\text { High IL-1 } 1 \beta \text { release leading to severe } \\
\text { disease with tissue destruction, high } \\
\text { bacterial and neutrophil counts }\end{array}$ \\
\hline
\end{tabular}

Fig. 7 | Host determinants of disease severity in acute cystitis; mechanism of IL-1 $\beta$ and SP hyperactivation. Acute cystitis is a disease caused by excessive inflammation in the urinary bladder, accompanied by pain, frequency of micturition and urgency. The molecular basis of disease is illustrated here, focusing on the host determinants of disease and especially the IL-1 $\beta$ response. Left panel: bacteria engage urothelial cell receptors and trigger the expression of pro-IL- $1 \beta$ by activating Toll-like receptor 4(TLR4) signalling through the MyD88 adaptor pathway and the transcription factor NF- $\mathrm{kB}$. IL-1 $\beta$ is essential for disease pathogenesis, as shown by the protection from acute cystitis in $l l 1 b^{-/-}$and $T l r 4^{-/-}$mice, which lack the pro-IL-1 $\beta$ response to infection with uropathogenic Escherichia coli (UPEC) strains. Middle panel: bacteria activate the NLRP3 inflammasome via a second signal involving mechanisms such as ion fluxes. Activated caspase 1 (Casp-1) then cleaves pro-IL-1 $\beta$ to its mature and active form. The release of IL-1 $\beta$ triggers inflammation in the bladder and creates transient, mild disease in C57BL/6 wild-type mice. Right panel: in inflammasomedeficient mice an alternative IL-1 $\beta$-processing mechanism takes over. Mice lacking the NLRP3 inflammasome owing to single gene deletions ( $\mathrm{Asc}^{-1-}$ or $\mathrm{Nlrp}^{-1-}$ mice) develop an IL-1 $\beta$ hyper-activation syndrome explained by excessive processing by matrix metalloproteinase 7 (MMP7) ${ }^{33}$. In addition, ASC and NLRP3 regulate the expression of the pain receptor neurokinin 1 receptor (NK1R; encoded by TACR1), by acting as transcriptional repressors of both MMP7 and TACR1. ASC and NLRP3, therefore, act as molecular gatekeepers, defining the level of transcription of the pro-inflammatory response driven by pro-IL-1 $\beta$, and the pain response, driven by NK1R and substance P (SP). In Asc-deficient or Nlrp3-deficient mice, in which this gatekeeping function is lost, UPEC-infected mice develop severe acute cystitis, mediated by excessive MMP7 cleavage of pro-IL-1 $\beta$ and by overproduction of NK1R ${ }^{33,35}$. ASC, apoptosis-associated speck-like protein containing a CARD; I $\mathrm{\kappa}$, inhibitor of $\kappa \mathrm{B}$; MyD88, myeloid differentiation primary response protein 88 ; NF- $\kappa B$, nuclear factor- $\mathrm{B}$; $\mathrm{P}$, phosphate group; TIRAP, Toll/interleukin 1 receptor-domain-containing adaptor protein. Adapted from REF. ${ }^{33}$, CC BY 4.0 (https://creativecommons.org/licenses/ by/4.0/). 


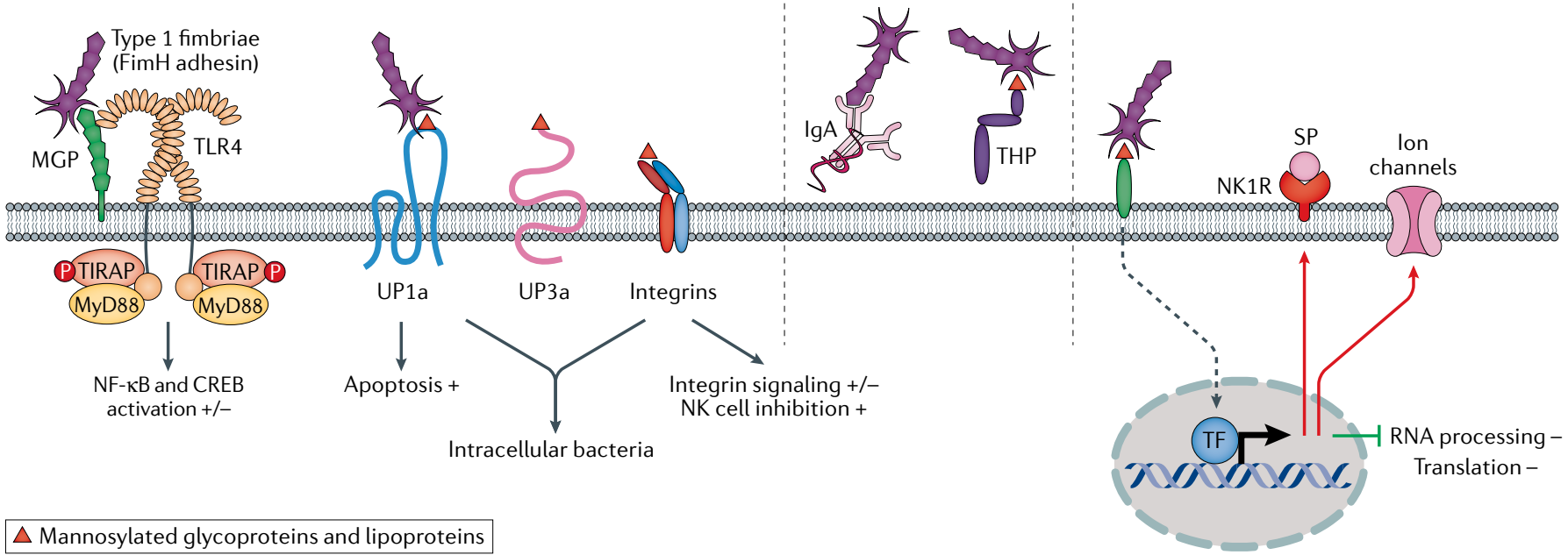

Fig. 8 | Host recognition and response parameters associated with type 1 fimbriae. Left panel: examples of receptors for type 1 fimbriae. The FimH adhesin binds mannosylated host cell glycoconjugate receptors and activates Toll-like receptor 4 (TLR4) signalling, mainly involving the myeloid differentiation primary response protein 88 (MyD88) adaptor protein arm of this signalling pathway ${ }^{60}$, resulting in pro-inflammatory effects in mice. Binding to uroplakin particles (UP1a, UP1b, UP2 and UP3a) promotes bacterial internalization by mammalian cells; $\beta 1$ and $\alpha 3$ integrins modulate $\mathrm{F}$-actin dynamics and CD48 receptors trigger TNF responses in mucosal mast cells. Type 1 fimbriae have also been proposed to trigger apoptosis ${ }^{223}$. Middle panel: soluble receptors act as binding antagonists. Soluble lgA immunoglobulins or Tamm-Horsfall protein (THP) (or uromodulin) that carry mannose residues bind $\mathrm{FimH}$ and prevent the bacteria from engaging cellular receptors in the urinary tract. Right panel: response of patients to type 1 fimbriated bacteria. The transcriptional response to type 1 fimbriae has been characterized in patients carrying Escherichia coli $83972 \mathrm{fim}^{79}$. E. coli 83972 fim acts as a broad inhibitor of RNA processing and translation in human cells. In addition, type 1 fimbriae potentiate ion channel activation and solute carrier expression in the patients. In human cells, FimH triggers increased neurokinin receptor (NK1R) expression. CREB, cAMP response element-binding protein; MGP, mannosylated glycoprotein; $N F-\kappa B$, nuclear factor- $\kappa B$; NK, natural killer; P, phosphate group; SP, substance; TF, transcription factor; TIRAP, Toll/interleukin 1 receptordomain-containing adaptor protein. Adapted from REF. ${ }^{6}$, Springer Nature Limited, and from REF. ${ }^{79}$, CC BY 4.0 (https://creativecommons.org/licenses/ by/4.0/). mice carrying homozygous deletions have increased susceptibility to acute cystitis ${ }^{139,188,189}$ (TABLE 1). The bladders of UPEC-infected Tlr $5^{-1-}$ mice showed prominent submucosal oedema with leukocyte infiltration, as well as focal microabscesses and accumulation of leukocyte-rich exudates on the bladder surface ${ }^{139}$. In infected Tlr $5^{-1-}$ mice, bacteria were predominantly observed on the surface of the urothelium, with no evidence of intracellular bacterial communities. TLR5 polymorphisms have also been observed in patients prone to recurrent $\mathrm{UTI}^{83}$ but genetic variation affecting Thp and Cox 2 has not been reported.

\section{Molecular basis of pain}

Mechanisms of infection-associated pain have been studied in several infection models, including S. aureusmediated pain and Clostridium difficile-induced colitis ${ }^{10,191}$. Pain is a hallmark of acute cystitis; however, the mechanism by which infection triggers pain sensing in the urinary tract has been unclear. Acute cystitis strains directly activate nerve cells in vitro and in the urinary bladder ${ }^{35}$ (FIG. 8). The pain-sensing machinery involves the neurokinin 1 receptor (NK1R) and substance $\mathrm{P}$ (SP), which are activated in isolated nerve cells and in the urinary bladder mucosa. This response was potentiated by IL- $1 \beta$ in vivo in infected mice and was inhibited by IL-1R antagonists, demonstrating an interdependence between the epithelial and nerve cell response circuits ${ }^{35}$. These results suggest that NK1R and SP influence the severity of acute cystitis through a neuroepithelial activation loop that controls pain and mucosal inflammation.

NK1R and SP have been identified as novel targets for immunomodulatory therapy as well as biomarkers of acute cystitis. IL-1 receptor antagonists and NK1R inhibitors have been used successfully to inhibit infection-induced pain in mice with acute cystitis ${ }^{33}$. Pain behaviour, defined by locomotion, hunching and rearing behaviour, was markedly attenuated, in parallel with inflammation and pathology.

Clinical relevance was supported by off-label treatment of patients with bladder pain using an IL-1 receptor antagonist. A rapid reduction in pain and increase in the quality of life were recorded, suggesting considerable improvement after treatment.

\section{Innate immune mediators}

Early studies demonstrated that bladder epithelial cells produce cytokines in response to infection; a novel concept at the time ${ }^{93,165,192,193}$. Since then, numerous cytokines and chemokines have been detected in the urinary tract that mediate different aspects of the disease response $\mathrm{e}^{30,194-198}$. The pro-inflammatory cytokine TNF, is rapidly and transiently expressed during the first days of infection ${ }^{165,195}$ and supports neutrophil recruitment and bacterial clearance in a mouse model of $\mathrm{UTI}^{199}$. The granulocyte colony-stimulating factor (G-CSF; also known as CSF3) is secreted during infection, and depletion using neutralizing antibodies decreased neutrophil recruitment into the bladder and increased bacterial clearance 
in infected mice ${ }^{195}$. G-CSF induces the maturation of progenitor cells into neutrophils and promotes their systemic circulation $^{200-202}$. The chemokine CXCL12 is expressed in mice within hours of $E$. coli infection and promotes NK and $\mathrm{T}$ cell infiltration into the bladder ${ }^{203}$. IL-17 influences disease severity and is differentially expressed between female and male mice following bladder infection ${ }^{204}$. IL-17-depleted mice have reduced early urine neutrophils and increased bacterial burdens ${ }^{205}$ and IL-17 neutralization at the onset of infection leads to chronic UTI in female mice ${ }^{204}$. Mechanistic studies further suggest that IL-17 might be crucial in restoring mucosal integrity after infection, also affecting chronicity ${ }^{205,206}$.

\section{Type 1 fimbriae}

Why acute cystitis strains mainly infect the bladder and elicit a host response with molecular characteristics different from those seen in the kidneys remains unclear ${ }^{89}$. Epidemiological studies have detected a high frequency of type 1 fimbriae among acute cystitis strains, but type 1 fimbrial expression does not show a clear disease association $^{64,89}$. Gene expression studies in infected mice suggest that type 1 fimbriae are expressed in the urinary tract, but the fimbriae were undetectable in acute isolates from women with $\mathrm{UTI}^{207}$. Haemolysin and the prs $\mathrm{G}_{966}$ type of $\mathrm{P}$ fimbriae have been proposed to occur more often in acute cystitis strains than in other E. coli, but this association varies between study populations ${ }^{208,209}$.

Type 1 fimbriae act as virulence factors in the mouse urinary tract and tissue interaction mechanisms have been extensively investigated ${ }^{120,121,210,211}$. Type 1 fimbriae improve bacterial attachment to the bladder mucosa, where several mannosylated host cell glycoconjugates act as receptors ${ }^{212-217}$ (FIG. 8). The FimH adhesin binds to the Tamm-Horsfall protein (THP; also known as uromodulin) ${ }^{215}$, secretory $\operatorname{IgA}^{212}$, uroplakins (UPs) ${ }^{216}$ and CD48 on mucosal mast cells ${ }^{214}$, as well as integrins $\beta 1$ and $\alpha 3\left(\right.$ REF. $^{217}$ ). Type 1 fimbriae have been proposed to facilitate the invasion of mucosal cells and bacterial persistence and cystitis in mice ${ }^{218,219}$. In humans, early findings of intracellular bacterial communities ${ }^{220}$ have not been confirmed.

Binding of type 1 fimbriae to UP1a stimulates the exfoliation of bladder epithelial cells, thereby shedding adherent bacteria and increasing access to underlying tissues $^{86,221}$. In response to FimH-FimC binding, UP3a phosphorylation activates casein kinase II and triggers calcium fluxes ${ }^{222,223}$ and cyclic AMP regulates the incorporation of $E$. coli into fusiform vesicles and exocytosis of E. coli from bladder epithelial cells. Intraperitoneal forskolin treatment, which elevates intracellular levels of cyclic AMP, was reported to eliminate $>99 \%$ of intracellular E. coli by exocytosis without affecting bacterial viability ${ }^{224}$.

The relevance of these mechanisms to disease severity in acute cystitis remains unclear. Clear disease phenotypes have not been observed and consequences of these molecular effects for disease have not been clearly defined.

\section{Mast cells in acute cystitis}

Mast cell activation is important in the bladder mucosa ${ }^{225}$ and known effects of histamine and other mast-cell mediators correlate with the neuroinflammatory response and symptoms of acute cystitis ${ }^{226}$. Pre-stored TNF-containing granules within mast cells have been shown to burst and participate in the recruitment and activation of neutrophils ${ }^{225}$, and TNF activation and neutrophil recruitment was reduced in mast cell-deficient mice ${ }^{225}$. Mast cells are activated by epithelial release of IL-1 $\beta$, ATP, IL-33 and $\beta$-defensins ${ }^{28}$, and the histamine response magnitude correlated positively with the number of adherent type 1 fimbriated bacteria. Type 1 fimbriae interactions with mast cell glycosyl-phosphatidylinositol receptors (CD48) were shown to affect the uptake of adherent bacteria as well as mast cell degranulation ${ }^{227}$. The role of mast cells and their link to type 1 fimbriae are interesting and potentially important, but their role in host resistance and disease severity requires further study.

The shedding of superficial bladder epithelium during UTI is well known and UPEC infection was shown to trigger rapid desquamation in the $1980 \mathrm{~s}^{228}$. In later studies, cell shedding was attributed to granule-releasing mast cells as a mechanism to reduce the tissue-associated bacterial load ${ }^{229,230}$. In a mouse model of induced recurrent cystitis, a lack of superficial terminal differentiation markers in umbrella cells was interpreted to indicate a lack of tissue repair ${ }^{231}$. Susceptibility to recurrent UTI was positively correlated with cyclooxygenase 2 (COX2) expression, as would be expected from effects on innate immunity $^{232}$, but the effects of bacterial clearance varied, suggesting additional variable ${ }^{233}$. Moreover, a strong $\mathrm{T}_{\mathrm{H}} 2$ response was proposed to aid in repairing the superficial bladder epithelium following infection-triggered exfoliation of this barrier ${ }^{206}$.

Taken together, these studies highlight the importance of host susceptibility for disease in the urinary bladder and identify IL-1 hyperactivation as a potent disease determinant with immediate human relevance. In addition, pro-inflammatory loops involving pain sensors provide an explanation for the pain response, especially in acute cystitis. Clinical studies provide support for these mechanisms, as IL-1 and the neuropeptide substance $\mathrm{P}$ both show elevated levels in acute cystitis patients, compared with individuals with $\mathrm{ABU}$.

Thus, these findings indicate that the use of immune response biomarkers should be explored to distinguish different forms of UTI and evaluate the level of immune activation in the patient.

\section{Parallels with COVID-19 infection}

The protective role of innate immunity and detrimental effects of excessive immune activation have become very obvious during the COVID-19 pandemic. The strategies of innate immune activation are conserved and the innate immune response to UTI shares several characteristics with the response seen in patients with COVID-19. For example, viral and bacterial ligands guide TLR4 activation ${ }^{234,235}$. TLR4 has shown strong protein-protein interaction with the spike glycoprotein of SARS-CoV-2, leading to excessive TLR4 activation ${ }^{236}$. Furthermore, SARS-CoV-2 has an affinity for linoleic acid $^{237}$, suggesting a potential parallel to $\mathrm{P}$ fimbriae, which bind to glycosphingolipid receptors and trigger the release of ceramide, consisting of sphingosine and 
fatty acids, which acts as a signalling intermediate in TLR4 activation ${ }^{114}$. Severely ill patients with COVID-19 have excessive production of pro-inflammatory cytokines and chemokines including IL-6 (REF. ${ }^{238}$ ), which is associated with disease severity and outcome in APN and urosepsis as well ${ }^{239}$. Finally, IL-1 $\beta$ levels are dramatically increased in patients with COVID-19 and MMP levels are elevated ${ }^{240}$, possibly indicating that the non-canonical processing mechanism of pro-IL- $1 \beta$ by MMP7, which is seen in acute cystitis, might contribute to this excessive response.

\section{Conclusions}

UTIs are a common cause of morbidity and mortality and impair the quality of life for large numbers of individuals. Every other woman is affected by acute cystitis at least once and recurrences and chronicity are extremely common. APN in childhood is a major cause of renal scar formation and renal growth retardation, increasing the risk of hypertension and chronic renal disease requirement for dialysis or transplantation in adulthood and also premature birth in women. Antibiotics have provided an essential therapeutic option, but owing to the rapid increase in antibiotic resistance, detailed molecular questions need answers in order to design effective novel interventions with sufficient precision.
Specific molecular insights can, for the first time, provide appropriate tools to evaluate disease severity, susceptibility and future patient risk.

In this Review, we show how an overactive innate immune response can become a susceptibility factor in UTI, with debilitating consequences for the patients. The data also distinguish APN from acute cystitis, at the molecular level ${ }^{32-34}$. APN susceptibility is enhanced by a transcription factor imbalance and by immunodeficiencies affecting neutrophil-dependent bacterial clearance ${ }^{34}$. By contrast, acute cystitis is caused by IL- $1 \beta$ hyperactivation owing to mutations that inactivate the inflammasome constituents ASC and NLRP3. A compensatory route of pro-IL-1 processing by the MMP7 protease, is shown to result in excessive cleavage of pro-IL- $1 \beta$, causing severe disease ${ }^{33}$. Thus, even when mice are infected with the same E. coli strain, the host decides the outcome.

The findings emphasize how weaknesses of the host create innate immune imbalances and immune hyper-activation disorders leading to disease. The results also provide the rationale for immunomodulation as a new therapeutic tool to deliberately modify host susceptibility, control the host response and avoid severe disease.

Published online 15 June 2021
1. Svanborg, C. et al. Uropathogenic Escherichia coli as a model of host-parasite interaction. Curr. Opin. Microbiol. 9, 33-39 (2006)

2. Rittirsch, D., Flierl, M. A. \& Ward, P. A. Harmful molecular mechanisms in sepsis. Nat. Rev. Immunol. 8, 776-787 (2008)

3. Beutler, B. Innate immunity: an overview. Mol. Immunol. 40, 845-859 (2004).

4. Ferrandon, D., Imler, J. L., Hetru, C. \& Hoffmann, J. A. The Drosophila systemic immune response: sensing and signalling during bacterial and fungal infections. Nat. Rev. Immunol. 7, 862-874 (2007).

5. Kumar, H., Kawai, T. $\&$ Akira, S. Pathogen recognition by the innate immune system. Int. Rev. Immunol. 30, 16-34 (2011).

6. Ragnarsdottir, B., Lutay, N., Gronberg-Hernandez, J., Koves, B. \& Svanborg, C. Genetics of innate immunity and UTI susceptibility. Nat. Rev. Urol. 8, 449-468 (2011).

7. Casanova, J. L. Severe infectious diseases of childhood as monogenic inborn errors of immunity. Proc. Natl Acad. Sci. USA 112, E7128-E7137 (2015).

8. Telenti, A. \& di lulio, J. Regulatory genome variants in human susceptibility to infection. Hum. Genet. 139 759-768 (2020).

9. Hagberg, L. et al. Difference in susceptibility to gramnegative urinary tract infection between $\mathrm{C} 3 \mathrm{H} / \mathrm{HeJ}$ and $\mathrm{C} 3 \mathrm{H} / \mathrm{HeN}$ mice. Infect. Immun. 46, 839-844 (1984).

10. Poltorak, A. et al. Defective LPS signaling in $\mathrm{C} 3 \mathrm{H} / \mathrm{HeJ}$ and C57BL/10ScCr mice: mutations in TIr4 gene. Science 282, 2085-2088 (1998).

11. Abbo, L. M. \& Hooton, T. M. Antimicrobial stewardship and urinary tract infections. Antibiotics 3, 174-192 (2014)

12. WHO. Antibiotic resistance. Fact sheets. $W H O$ https://www.who.int/news-room/fact-sheets/detail/ antimicrobial-resistance (2020)

13. Wagenlehner, F. M. E. et al. Epidemiology, definition and treatment of complicated urinary tract infections. Nat. Rev. Urol. 17, 586-600 (2020).

14. Kass, E. H. Asymptomatic infections of the urinary tract. Trans. Assoc. Am. Physicians 69, 56-64 (1956).

15. Kunin, C. Detection, prevention and management of urinary tract infections. (Lea and Febiger, 1987).

16. Stamm, W. E. \& Norrby, S. R. Urinary tract infections: disease panorama and challenges. J. Infect. Dis. 183 (Suppl. 1), S1-S4 (2001).

17. Smith, A. L. et al. Treatment and prevention of recurrent lower urinary tract infections in women: a rapid review with practice recommendations. J. Urol. 200, 1174-1191 (2018).
18. Lipsky, B. A. Urinary tract infections in men. Ann. Intern. Med. 110, 138-150 (1989).

19. Krieger, J. N., Ross, S. O. \& Simonsen, J. M. Urinary tract infections in healthy university Men. J. Urol. 149 1046-1048 (1993)

20. Porter, P. J., Spievack, A. R. \& Kass, E. H. Endotoxinlike activity of serum from patients with severe localized infections. N. Engl. J. Med. 271, 445-447 (1964).

21. Nordenstam, G. R., Brandberg, C. A., Oden, A. S. Svanborg Eden, C. M. \& Svanborg, A. Bacteriuria and mortality in an elderly population. N. Engl. J. Med. 314, 1152-1156 (1986).

22. Martin, G. S., Mannino, D. M. \& Moss, M. The effect of age on the development and outcome of adult sepsis. Crit. Care Med. 34, 15-21 (2006).

23. Gharbi, M. et al. Antibiotic management of urinary tract infection in elderly patients in primary care and its association with bloodstream infections and all cause mortality: population based cohort study. BMJ 364, I525 (2019).

24. Martinell, J. et al. Detection of urographic scars in girls with pyelonephritis followed for 13-38 years. Pediatr. Nephrol. 14, 1006-1010 (2000).

25. Wennerstrom, M., Hansson, S., Jodal, U., Sixt, R. \& Stokland, E. Renal function 16 to 26 years after the first urinary tract infection in childhood. Arch. Pediatr. Adolesc. Med. 154, 339-345 (2000).

26. Toffolo, A., Ammenti, A. \& Montini, G. Long-term clinical consequences of urinary tract infections during childhood: a review. Acta Paediatr. 101, 1018-1031 (2012).

27. Geback, C. et al. Twenty-four-hour ambulatory blood pressure in adult women with urinary tract infection in childhood. J. Hypertens. 32, 1658-1664 (2014).

28. Abraham, S. N. \& Miao, Y. The nature of immune responses to urinary tract infections. Nat. Rev. Immunol. 15, 655 (2015).

29. Ambite, I. et al. Susceptibility to urinary tract infection: benefits and hazards of the antibacterial host response. Microbiol. Spectr. https://doi.org/ 10.1128/microbiolspec.UTI-0019-2014 (2016).

30. Lacerda Mariano, L. \& Ingersoll, M. A. The immune response to infection in the bladder. Nat. Rev. Urol. 17, 439-458 (2020)

31. Frendeus, B. et al. Interleukin 8 receptor deficiency confers susceptibility to acute experimental pyelonephritis and may have a human counterpart. J. Exp. Med. 192, 881-890 (2000).

32. Fischer, H. et al. Pathogen specific, IRF3-dependent signaling and innate resistance to human kidney infection. PLoS Pathog. 6, e1001109 (2010).
33. Ambite, I. et al. Molecular basis of acute cystitis reveals susceptibility genes and immunotherapeutic targets. PLoS Pathog. 12, e 1005848 (2016).

34. Puthia, M. et al. IRF7 inhibition prevents destructive innate immunity-A target for nonantibiotic therapy of bacterial infections. Sci. Transl. Med. 8, 336ra359 (2016).

35. Butler, D. S. C. et al. Neuroepithelial control of mucosal inflammation in acute cystitis. Sci. Rep. 8 , 11015 (2018).

36. Ambite, I. et al. Active bacterial modification of the host environment through RNA polymerase II inhibition. J. Clin. Invest. 131, e140333 (2021).

37. Andersson, P. et al. Persistence of Escherichia coli bacteriuria is not determined by bacterial adherence. Infect. Immun. 59, 2915-2921 (1991).

38. Ghosh, A. R. Appraisal of microbial evolution to commensalism and pathogenicity in humans. Clin. Med. Insights Gastroenterol. 6, 1-12 (2013).

39. Lindberg, U. Asymptomatic bacteriuria in school girls. V. The clinical course and response to treatment. Acta Paediatr. Scand. 64, 718-724 (1975).

40. Nicolle, L. E. Asymptomatic bacteriuria and bacterial interference. Microbiol. Spectr. https://doi.org/ 10.1128/microbiolspec.UTI-0001-2012 (2015).

41. Bonkat, G. et al. EAU guidelines on urological infections. 22-26 (European Association of Urology, 2017).

42. Nicolle, L. E. et al. Clinical practice guideline for the management of asymptomatic bacteriuria: 2019 update by the Infectious Diseases Society of America. Clin. Infect. Dis. 68, 1611-1615 (2019).

43. Colgan, R. Nicolle, L. E., McGlone, A \& Hooton, T. M. Asymptomatic bacteriuria in adults. Am. Fam. Physician 74, 985-990 (2006).

44. Nicolle, L. E. Urinary tract infections in the older adult. Clin. Geriatr. Med. 32, 523-538 (2016).

45. Hansson, S., Jodal, U., Lincoln, K. \& Svanborg-Eden, C. Untreated asymptomatic bacteriuria in girls: II Effect of phenoxymethylpenicillin and erythromycin given for intercurrent infections. BMJ 298, 856-859 (1989).

46. Cai, T et al. The role of asymptomatic bacteriuria in young women with recurrent urinary tract infections: to treat or not to treat? Clin. Infect. Dis. 55, 771-777 (2012).

47. Hagberg, L., Leffler, H. \& Svanborg-Edén, C. Non-antibiotic prevention of urinary tract infection. Infection 12, 132-137 (1984).

48. Wult, B. et al. Urodynamic factors influence the duration of Escherichia coli bacteriuria in deliberately colonized cases. J. Urol. 159, 2057-2062 (1998). 
49. Darouiche, R. O. et al. Pilot trial of bacterial interference for preventing urinary tract infection. Urology 58, 339-344 (2001).

50. Sunden, F., Hakansson, L., Ljunggren, E. \& Wullt, B. Escherichia coli 83972 bacteriuria protects against recurrent lower urinary tract infections in patients with incomplete bladder emptying. J. Urol. 184, 179-185 (2010).

51. Hull, R. et al. Urinary tract infection prophylaxis using Escherichia coli 83972 in spinal cord injured patients. J. Urol. 163, 872-877 (2000)

52. Darouiche, R. O., Thornby, J. I., Cerra-Stewart, C., Donovan, W. H. \& Hull, R. A. Bacterial interference for prevention of urinary tract infection: a prospective, randomized, placebo-controlled, double-blind pilot trial. Clin. Infect. Dis. 41, 1531-1534 (2005).

53. Zdziarski, J. et al. Host imprints on bacterial genomesrapid, divergent evolution in individual patients. PLoS Pathog. 6, e1001078 (2010).

54. Salvador, E. et al. Comparison of asymptomatic bacteriuria Escherichia coli isolates from healthy individuals versus those from hospital patients shows that long-term bladder colonization selects for attenuated virulence phenotypes. Infect. Immun. 80, 668-678 (2012)

55. Nicolle, L. E. Asymptomatic bacteriuria. Curr. Opin. Infect. Dis. 27, 90-96 (2014).

56. Zdziarski, J., Svanborg, C., Wullt, B., Hacker, J. \& Dobrindt, U. Molecular basis of commensalism in the urinary tract: low virulence or virulence attenuation? Infect. Immun. 76, 695-703 (2008).

57. Lutay, N. et al. Bacterial control of host gene expression through RNA polymerase II. J. Clin. Invest. 123, 2366-2379 (2013)

58. Ragnarsdottir, B. et al. Toll-like receptor 4 promoter polymorphisms: common TLR4 variants may protect against severe urinary tract infection. PLOS ONE 5 , e 10734 (2010).

59. Gronberg-Hernandez, J., Sunden, F., Connolly, J., Svanborg, C. \& Wullt, B. Genetic control of the variable innate immune response to asymptomatic bacteriuria. PLoS ONE 6, e28289 (2011).

60. Fischer, H., Yamamoto, M., Akira, S., Beutler, B. \& Svanborg, C. Mechanism of pathogen-specific TLR4 activation in the mucosa: fimbriae, recognition receptors and adaptor protein selection. Eur. J. Immunol. 36, 267-277 (2006)

61. Backhed, F., Meijer, L., Normark, S. \& Richter-Dahlfors, A. TLR4-dependent recognition of lipopolysaccharide by epithelial cells requires sCD 14. Cell Microbiol. 4, 493-501 (2002).

62. Samuelsson, P., Hang, L., Wullt, B., Irjala, H. \& Svanborg, C. Toll-like receptor 4 expression and cytokine responses in the human urinary tract mucosa. Infect. Immun. 72, 3179-3186 (2004).

63. Svanborg-Eden, C., Hanson, L. A., Jodal, U., Lindberg, U. \& Akerlund, A. S. Variable adherence to normal human urinary-tract epithelial-cells of Escherichia-coli strains associated with various forms of urinary-tract infection. Lancet 2, 490-492 (1976).

64. Hagberg, L. et al. Adhesion, hemagglutination, and virulence of Escherichia coli causing urinary tract infections. Infect. Immun. 31, 564-570 (1981).

65. Bergsten, G., Wullt, B. \& Svanborg, C. Escherichia coli, fimbriae, bacterial persistence and host response induction in the human urinary tract. Int. J. Med. Microbiol. 295, 487-502 (2005).

66. Hull, R. A et al. Virulence properties of Escherichia coli 83972 , a prototype strain associated with asymptomatic bacteriuria. Infect. Immun. 67, 429-432 (1999).

67. Mabbett, A. N. et al. Virulence properties of asymptomatic bacteriuria Escherichia coli. Int. J. Med. Microbiol. 299, 53-63 (2009).

68. Takahashi, A. et al. Escherichia coli isolates associated with uncomplicated and complicated cystitis and asymptomatic bacteriuria possess similar phylogenies, virulence genes, and O-serogroup profiles. J. Clin. Microbiol. 44, 4589-4592 (2006)

69. Roos, V., Schembri, M. A., Ulett, G. C. \& Klemm, P. Asymptomatic bacteriuria Escherichia coli strain 83972 carries mutations in the foc locus and is unable to express F1C fimbriae. Microbiology 152, 1799-1806 (2006).

70. Wullt, B. et al. P fimbriae enhance the early establishment of Escherichia coli in the human urinary tract. Mol. Microbiol. 38, 456-464 (2000).

71. Sims, R. J. 3rd, Belotserkovskaya, R. \& Reinberg, D. Elongation by RNA polymerase II: the short and long of it. Genes Dev. 18, 2437-2468 (2004).

72. Fuda, N. J., Ardehali, M. B. \& Lis, J. T. Defining mechanisms that regulate RNA polymerase II transcription in vivo. Nature 461, 186-192 (2009).
73. Selth, L. A., Sigurdsson, S. \& Svejstrup, J. O. Transcript elongation by RNA polymerase II. Annu. Rev. Biochem. 79, 271-293 (2010)

74. Uehara, T., Dinh, T. \& Bernhardt, T. G. LytM-domain factors are required for daughter cell separation and rapid ampicillin-induced lysis in Escherichia coli. J. Bacteriol. 191, 5094-5107 (2009).

75. Uehara, T., Parzych, K. R., Dinh, T. \& Bernhardt, T. C. Daughter cell separation is controlled by cytokinetic ring-activated cell wall hydrolysis. EMBO J. 29 , 1412-1422 (2010).

76. Poltorak, A. et al. Genetic and physical mapping of the Lps locus: identification of the Toll- 4 receptor as a candidate gene in the critical region. Blood Cell Mol. Dis. 24, 340-355 (1998)

77. Beutler, B. TIr4: central component of the sole mammalian LPS sensor. Curr. Opin. Immunol. 12 20-26 (2000)

78. Shahin, R., Engberg, I., Hagberg, L. ¿ Svanborg-Edén, C. Neutrophil recruitment and bacterial clearance correlated with LPS responsiveness in local gramnegative infection J. Immunol. 138, 3475-3480 (1987).

79. Ambite, l. et al. Fimbriae reprogram host gene expression - divergent effects of $\mathrm{P}$ and type 1 fimbriae. PLoS Pathog. 15, e1007671 (2019).

80. Yadav, M. et al. Inhibition of TIR domain signaling by TcpC: MyD88-dependent and independent effects on Escherichia coli virulence. PLoS Pathog. 6, e1001120 (2010).

81. Hawn, T. R. et al. Genetic variation of the human urinary tract innate immune response and asymptomatic bacteriuria in women. PLOS ONE 4, e8300 (2009).

82. Ragnarsdōttir, B. et al. TLR- and CXCR1-dependent innate immunity: insights into the genetics of urinary tract infections. Eur. J. Clin. Invest. 38, 12-20 (2008).

83. Hawn, T. R. et al. Toll-like receptor polymorphisms and susceptibility to urinary tract infections in adult women. PLOS ONE 4, e5990 (2009).

84. Welch, R. A. et al. Extensive mosaic structure revealed by the complete genome sequence of uropathogenic Escherichia coli. Proc. Natl Acad. Sci. USA 99, 17020-17024 (2002)

85. Connell, H. et al. Type 1 fimbrial expression enhances Escherichia coli virulence for the urinary tract. Proc. Natl Acad. Sci. USA 93, 9827-9832 (1996).

86. Mulvey, M. A. et al. Induction and evasion of host defenses by type 1-piliated uropathogenic Escherichia coli. Science 282, 1494-1497 (1998).

87. Martinez, J. J., Mulvey, M. A., Schilling, J. D. Pinkner, J. S. \& Hultgren, S. J. Type 1 pilus-mediated bacterial invasion of bladder epithelial cells. EMBO J. 19, 2803-2812 (2000)

88. Schembri, M. A. \& Klemm, P. Biofilm formation in a hydrodynamic environment by novel fimH variants and ramifications for virulence. Infect. Immun. 69 1322-1328 (2001).

89. Johnson, J. R. Virulence factors in Escherichia coli urinary tract infection. Clin. Microbiol. Rev. 4 80-128 (1991).

90. Zupan, J. Perinatal mortality in developing countries. N. Engl. J. Med. 352, 2047-2048 (2005).

91. Wagenlehner, F. M., Tandogdu, Z. \& Bjerklund Johansen, T. E. An update on classification and management of urosepsis. Curr. Opin. Urol. 27 133-137 (2017)

92. Liang, L. D. et al. Predictors of mortality in neonates and infants hospitalized with sepsis or serious infections in developing countries: a systematic review. Front. Pediatr. 6, 277 (2018)

93. de Man, P. et al. Interleukin- 6 induced at mucosal surfaces by Gram-negative bacterial infection. Infect. Immun. 57, 3383-3388 (1989).

94. Hedges, S., Agace, W. \& Svanborg, C. Epithelial cytokine responses and mucosal cytokine networks. Trends Microbiol. 3, 266-270 (1995)

95. Geback, C. et al. Renal function in adult women with urinary tract infection in childhood. Pediatr. Nephrol. 30, 1493-1499 (2015)

96. Swerkersson, S., Jodal, U., Sixt, R., Stokland, E. \& Hansson, S. Urinary tract infection in small children the evolution of renal damage over time. Pediatr. Nephrol. 32, 1907-1913 (2017).

97. Liang, D. et al. DNA copy number variations in children with vesicoureteral reflux and urinary tract infections. PLOS ONE 14, e0220617 (2019).

98. Gluba, A. et al. The role of Toll-like receptors in rena diseases. Nat. Rev. Nephrol. 6, 224-235 (2010).

99. Giamarellos-Bourboulis, E. J. et al. Early changes of CD4-positive lymphocytes and NK cells in patients with severe Gram-negative sepsis. Crit. Care 10 R166-R166 (2006).
100. Subashchandrabose, S. \& Mobley, H. L. T. Virulence and fitness determinants of uropathogenic Escherichia coli. Microbiol. Spectr. https://doi.org/10.1128/ microbiolspec.UTI-0015-2012 (2015).

101. Klein, R. D. \& Hultgren, S. J. Urinary tract infections: microbial pathogenesis, host-pathogen interactions and new treatment strategies. Nat. Rev. Microbiol. 18, 211-226 (2020)

102. de Man, P., Jodal, U., Lincoln, K. \& Svanborg-Edén, C. Bacterial attachment and inflammation in the urinary tract. J. Infect. Dis. 158, 29-35 (1988).

103. Linder, H., Engberg, I., Hoschutzky, H., Mattsby-Baltzer, I. \& Svanborg, C. Adhesiondependent activation of mucosal interleukin- 6 production. Infect. Immun. 59, 4357-4362 (1991).

104. Leffler, H. \& Svanborg-Eden, C. Glycolipid receptors for uropathogenic Escherichia coli on human erythrocytes and uroepithelial cells. Infect. Immun. 34, 920-929 (1981)

105. Caugant, D. A. et al. Genetic diversity in relation to serotype in Escherichia coli. Infect. Immun. 49, 407-413 (1985).

106. Dobrindt, U., Chowdary, M. G., Krumbholz, G. \& Hacker, J. Genome dynamics and its impact on evolution of Escherichia coli. Med. Microbiol. Immunol. 199, 145-154 (2010).

107. Rode, C. K., Melkerson-Watson, L. J., Johnson, A. T $\Sigma$ Bloch, C. A. Type-specific contributions to chromosome size differences in Escherichia coli. Infect. Immun. 67, 230-236 (1999).

108. Vejborg, R. M., Hancock, V., Schembri, M. A. \& Klemm, P. Comparative genomics of Escherichia coli strains causing urinary tract infections. Appl. Env. Microbiol. 77, 3268-3278 (2011)

109. Brzuszkiewicz, E. et al. How to become a uropathogen: comparative genomic analysis of extraintestinal pathogenic Escherichia coli strains. Proc. Natl Acad. Sci. USA 103, 12879-12884 (2006).

110. Lloyd, A. L., Henderson, T. A., Vigil, P. D. \& Mobley, H. L. Genomic islands of uropathogenic Escherichia coli contribute to virulence. J. Bacteriol. 191, 3469-3481 (2009)

111. Korhonen, T. K., Vaisanen, V., Saxen, H., Hultberg, H. \& Svenson, S. B. P-antigen-recognizing fimbriae from human uropathogenic Escherichia coli strains. Infect. Immun. 37, 286-291 (1982)

112. Otto, G., Sandberg, T., Marklund, B. I., Ulleryd, P. $\&$ Svanborg, C. Virulence factors and Pap genotype in Escherichia-coli isolates from women with acute pyelonephritis, with or without bacteremia. Clin. Infect. Dis. 17, 448-456 (1993).

113. Leffler, H. \& Svanborg-Edên, C. Chemical identification of a glycosphingolipid receptor for Escherichia coli attaching to human urinary tract epithelial cells and agglutinating human erythrocytes. FEMS Microbiol. Lett. 8, 127-134 (1980)

114. Hedlund, M., Svensson, M., Nilsson, A., Duan, R. D. \& Svanborg, C. Role of the ceramide-signaling pathway in cytokine responses to P-fimbriated Escherichia coli. J. Exp. Med. 183, 1037-1044 (1996)

115. Hedlund, M., Nilsson, A., Duan, R. D. ¿ Svanborg, C. Sphingomyelin, glycosphingolipids and ceramide signalling in cells exposed to P fimbriated Escherichia coli. Mol. Microbiol. 29, 1297-1306 (1998).

116. Yamamoto, M. et al. Essential role for TIRAP in activation of the signalling cascade shared by TLR2 and TLR4. Nature 420, 324-329 (2002)

117. Westerlund, B. et al. The O75X adhesin of uropathogenic Escherichia coli is a type IV collagenbinding protein. Mol. Microbiol. 3, 329-337 (1989)

118. Selvarangan, R. et al. Interaction of Dr adhesin with collagen type IV is a critical step in Escherichia coli renal persistence. Infect. Immun 72, 4827-4835 (2004).

119. Das, M. et al. Hydrophilic domain II of Escherichia coli Dr fimbriae facilitates cell invasion. Infect. Immun. 73 6119-6126 (2005).

120. Schaeffer, A. J., Schwan, W. R., Hultgren, S. J. \& Duncan, J. L. Relationship of type 1 pilus expression in Escherichia coli to ascending urinary tract infections in mice. Infect. Immun. 55, 373-380 (1987).

121. Mobley, H. L., Chippendale, G. R., Tenney, J. H., Hull, R. A. \& Warren, J. W. Expression of type 1 fimbriae may be required for persistence of Escherichia coli in the catheterized urinary tract. J. Clin. Microbiol. 25, 2253-2257 (1987).

122. Cavaillon, J. M. Exotoxins and endotoxins: inducers of inflammatory cytokines. Toxicon 149, 45-53 (2018).

123. Uhlen, P. et al. Alpha-haemolysin of uropathogenic $E$. coli induces $\mathrm{Ca} 2^{+}$oscillations in renal epithelial cells. Nature 405, 694-697 (2000).

124. Smith, Y. C., Rasmussen, S. B., Grande, K. K. Conran, R. M. \& O’Brien, A. D. Hemolysin of 
uropathogenic Escherichia coli evokes extensive shedding of the uroepithelium and hemorrhage in bladder tissue within the first 24 hours after intraurethral inoculation of mice. Infect. Immun. 76 2978-2990 (2008)

125. Hildebrand, A., Pohl, M. \& Bhakdi, S. Staphylococcus aureus alpha-toxin. Dual mechanism of binding to target cells. J. Biol. Chem. 266, 17195-17200 (1991).

126. Ludwig, A., Benz, R. \& Goebel, W. Oligomerization of Escherichia coli haemolysin (HlyA) is involved in pore formation. Mol. Gen. Genet. 241, 89-96 (1993).

127. Wilke, G. A. \& Bubeck Wardenburg, J. Role of a disintegrin and metalloprotease 10 in Staphylococcus aureus alpha-hemolysin-mediated cellular injury. Proc. Natl Acad. Sci. USA 107, 13473-13478 (2010).

128. Mills, M., Meysick, K. C. \& O’Brien, A. D. Cytotoxic necrotizing factor type 1 of uropathogenic Escherichia coli kills cultured human uroepithelial 5637 cells by an apoptotic mechanism. Infect. Immun. $\mathbf{6 8}$, 5869-5880 (2000)

129. Garcia, E. C., Brumbaugh, A. R. \& Mobley, H. L. Redundancy and specificity of Escherichia coli iron acquisition systems during urinary tract infection. Infect. Immun. 79, 1225-1235 (2011).

130. Henderson, L. C., Kadis, S. \& Chapman, W. L. Jr. Influence of iron on Corynebacterium renale-induced pyelonephritis in a rat experimental model. Infect. Immun. 21, 540-545 (1978).

131. Jacobson, S. H., Tullus, K., Wretlind, B. \& Brauner, A Aerobactin-mediated uptake of iron by strains of Escherichia coli causing acute pyelonephritis and bacteraemia. J. Infect. 16, 147-152 (1988).

132. Neilands, J. B. Siderophores: structure and function of microbial iron transport compounds. J. Biol. Chem. 270, 26723-26726 (1995)

133. Goetz, D. H. et al. The neutrophil lipocalin NGAL is a bacteriostatic agent that interferes with siderophoremediated iron acquisition. Mol. Cell 10, 1033-1043 (2002).

134. Smith, K. D. Iron metabolism at the host pathogen interface: lipocalin 2 and the pathogen-associated iroA gene cluster. Int. J. Biochem. Cell Biol. 39 1776-1780 (2007)

135. Ruiz, J. et al. Differences in virulence factors among clinical isolates of Escherichia coli causing cystitis and pyelonephritis in women and prostatitis in men. J. Clin. Microbiol. 40, 4445-4449 (2002).

136. Lane, M. C., Alteri, C. J., Smith, S. N. \& Mobley, H. L. Expression of flagella is coincident with uropathogenic Escherichia coli ascension to the upper urinary tract. Proc. Natl Acad. Sci. USA 104, 16669-16674 (2007).

137. Song, J., Bishop, B. L., Li, G., Duncan, M. J. \& Abraham, S. N. TLR4-initiated and cAMP-mediated abrogation of bacterial invasion of the bladder. Cell Host Microbe 1, 287-298 (2007).

138. Li, K., Feito, M. J., Sacks, S. H. \& Sheerin, N. S CD46 (membrane cofactor protein) acts as a human epithelial cell receptor for internalization of opsonized uropathogenic Escherichia coli. J. Immunol. 177, 2543-2551 (2006)

139. Andersen-Nissen, E. et al. Cutting edge: TIr5 $5^{-/-}$mice are more susceptible to Escherichia coli urinary tract infection. J. Immunol. 178, 4717-4720 (2007).

140. Song, J. \& Abraham, S. N. TLR-mediated immune responses in the urinary tract. Curr. Opin. Microbiol. 11, 66-73 (2008).

141. Burch-Smith, T. M. \& Dinesh-Kumar, S. P. The functions of plant TIR domains. Sci. STKE 2007, pe46 (2007)

142. Newman, R. M., Salunkhe, P., Godzik, A. \& Reed, J. C Identification and characterization of a novel bacterial virulence factor that shares homology with mammalian Toll/interleukin-1 receptor family proteins. Infect. Immun. 74, 594-601 (2006)

143. Cirl, C. et al. Subversion of Toll-like receptor signaling by a unique family of bacterial Toll/interleukin- 1 receptor domain-containing proteins. Nat. Med. 14 399-406 (2008).

144. Snyder, G. A. et al. Molecular mechanisms for the subversion of MyD88 signaling by TcpC from virulent uropathogenic Escherichia coli. Proc. Natl Acad. Sci. USA 110, 6985-6990 (2013).

145. Essuman, K. et al. TIR domain proteins are an ancient family of $\mathrm{NAD}^{+}$-consuming enzymes. Curr. Biol. $\mathbf{2 8}$ 421-430.e4 (2018)

146. Butler, D. S. C. et al. A bacterial protease depletes c-MYC and increases survival in mouse models of bladder and colon cancer. Nat. Biotechnol. https:// doi.org/10.1038/s41587-020-00805-3 (2021).

147. Stuelten, C. H., Parent, C. A. \& Montell, D. J. Cell motility in cancer invasion and metastasis: insights from simple model organisms. Nat. Rev. Cancer 18 296-312 (2018)

148. Croce, C. M. Oncogenes and cancer. N. Engl. J. Med. 358, 502-511 (2008).

149. Pelengaris, S., Khan, M. \& Evan, G. c-MYC: more than just a matter of life and death. Nat. Rev. Cancer 2 764-776 (2002).

150. Soucek, L. et al. Modelling Myc inhibition as a cancer therapy. Nature 455, 679-683 (2008).

151. Chen, H., Liu, H. D. \& Qing, G. L. Targeting oncogenic Myc as a strategy for cancer treatment. Signal Transduct. Target. Ther. 3, 5 (2018).

152. Lee, I. \& Suzuki, C. K. Functional mechanics of the ATP-dependent Lon protease-lessons from endogenous protein and synthetic peptide substrates. Biochim. Biophys. Acta 1784, 727-735 (2008).

153. Ramsay, G., Evan, G. I. \& Bishop, J. M. The protein encoded by the human proto-oncogene c-Myc. Proc. Natl Acad. Sci. USA 81, 7742-7746 (1984).

154. Mugrauer, G. \& Ekblom, P. Contrasting expression patterns of three members of the myc family of protooncogenes in the developing and adult mouse kidney. J. Cell Biol. 112, 13-25 (1991).

155. Jacobson, S. H., Eklof, O., Lins, L. E., Wikstad, I. \& Winberg, J. Long-term prognosis of post-infectious renal scarring in relation to radiological findings in childhood - a 27-year follow-up. Pediatr. Nephrol. 6 19-24 (1992)

156. Ching, C. B. et al. Interleukin-6/Stat3 signaling has an essential role in the host antimicrobial response to urinary tract infection. Kidney Int. 93, 1320-1329 (2018).

157. Lundstedt, A. C. et al. Inherited susceptibility to acute pyelonephritis: a family study of urinary tract infection J. Infect. Dis. 195, 1227-1234 (2007).

158. Artifoni, L. et al. Interleukin-8 and CXCR1 receptor functional polymorphisms and susceptibility to acute pyelonephritis. J. Urol. 177, 1102-1106 (2007).

159. Wathelet, M. G. et al. Virus infection induces the assembly of coordinately activated transcription factors on the IFN-beta enhancer in vivo. Mol. Cell 1, 507-518 (1998)

160. Sato, M. et al. Distinct and essential roles of transcription factors IRF-3 and IRF-7 in response to viruses for IFN-alpha/beta gene induction. Immunity $13,539-548(2000)$

161. Tan, C. K. et al. Genome-wide mapping of cystitis due to Streptococcus agalactiae and Escherichia coli in mice identifies a unique bladder transcriptome that signifies pathogen-specific antimicrobial defense against urinary tract infection. Infect. Immun. $\mathbf{8 0}$ 3145-3160 (2012)

162. Svanborg, C. et al. The 'innate' host response protects and damages the infected urinary tract. Ann. Med. 33, 563-570 (2001)

163. Agace, W., Hedges, S., Ceska, M. \& Svanborg, C. IL-8 and the neutrophil response to mucosal Gram negative infection. J. Clin. Invest. 92, 780-785 (1993)

164. Svensson, M., Irjala, H., Svanborg, C. \& Godaly, G. Effects of epithelial and neutrophil CXCR2 on innate immunity and resistance to kidney infection. Kidney Int. 74, 81-90 (2008).

165. Hedges, S. \& Svanborg C. The mucosal cytokine response to urinary tract infections. Int. J. Antimicrob. Agents 4, 89-93 (1994).

166. Wullt, B. et al. P-fimbriae trigger mucosal responses to Escherichia coli in the human urinary tract. Cell Microbiol. 3, 255-264 (2001)

167. Schilling, J. D., Mulvey, M. A., Vincent, C. D. Lorenz, R. G. \& Hultgren, S. J. Bacterial invasion augments epithelial cytokine responses to Escherichia coli through a lipopolysaccharide-dependent mechanism. J Immunol 166, 1148-1155 (2001).

168. Hang, L., Frendeus, B., Godaly, G. \& Svanborg, C. Interleukin-8 receptor knockout mice have subepithelial neutrophil entrapment and renal scarring following acute pyelonephritis. J. Infect. Dis. $182,1738-1748$ (2000).

169. Svensson, M. et al. Natural history of renal scarring in susceptible $\mathrm{mlL}^{-8 \mathrm{Rh}^{-1}}$ mice. Kidney Int. 67, 103-110 (2005).

170. Olszyna, D. P. et al. CXC chemokine receptor 2 contributes to host defense in murine urinary tract infection. J. Infect. Dis. 184, 301-307 (2001).

171. Lundstedt, A. C. et al. A genetic basis of susceptibility to acute pyelonephritis. PLOS ONE 2, e825 (2007).

172. Smithson, A. et al. Expression of interleukin-8 receptors (CXCR1 and CXCR2) in premenopausal women with recurrent urinary tract infections. Clin. Diagn. Lab. Immun. 12, 1358-1363 (2005)

173. Morrison, G., Kilanowski, F., Davidson, D. \& Dorin, J. Characterization of the mouse beta defensin 1, Defb 1 , mutant mouse model. Infect. Immun. 70, 3053-3060 (2002)

174. Chromek, M. et al. The antimicrobial peptide cathelicidin protects the urinary tract against invasive bacterial infection. Nat. Med. 12, 636 (2006)

175. Chromek, M. \& Brauner, A. Antimicrobial mechanisms of the urinary tract. J. Mol. Med. 86, 37-47 (2008).

176. Spencer, J. D. et al. Ribonuclease 7 is a potent antimicrobial peptide within the human urinary tract. Kidney Int. 80, 174-180 (2011).

177. Nielsen, K. L. et al. Role of urinary cathelicidin LL-37 and human beta-defensin 1 in uncomplicated Escherichia coli urinary tract infections. Infect. Immun 82, 1572-1578 (2014)

178. Paragas, N. et al. alpha-Intercalated cells defend the urinary system from bacterial infection. J. Clin. Invest 124, 2963-2976 (2014)

179. Jaillon, S. et al. The humoral pattern recognition molecule PTX3 is a key component of innate immunity against urinary tract infection. Immunity 40, 621-632 (2014)

180. Javor, J. et al. Association of interleukin-10 gene promoter polymorphisms with susceptibility to acute pyelonephritis in children. Folia Microbiol. 59 307-313 (2014)

181. Centi, S. et al. Upper urinary tract infections are associated with RANTES promoter polymorphism. J. Pediatr. 157, 1038-1040.e1 (2010).

182. Zhang, D. et al. A Toll-like receptor that prevents infection by uropathogenic bacteria. Science 303 , 1522-1526 (2004).

183. Norinder, B. S., Köves, B., Yadav, M., Brauner, A. \& Svanborg, C. Do Escherichia coli strains causing acute cystitis have a distinct virulence repertoire? Microb. Pathogenesis 52, 10-16 (2012).

184. Hooton, T. M. Clinical practice. Uncomplicated urinary tract infection. N. Engl. J. Med. 366, 1028-1037 (2012).

185. Driscoll, A. \& Teichman, J. M. How do patients with interstitial cystitis present? J. Urol. 166, 2118-2120 (2001).

186. Warren, J. W. et al. Urinary tract infection and inflammation at onset of interstitial cystitis/painful bladder syndrome. Urology 71, 1085-1090 (2008).

187. Ito, A. et al. Degradation of interleukin 1 beta by matrix metalloproteinases. J. Biol. Chem. 271 14657-14660 (1996)

188. Bates, J. M. et al. Tamm-Horsfall protein knockout mice are more prone to urinary tract infection: rapid communication. Kidney Int. 65, 791-797 (2004).

189. Dou, W. et al. Defective expression of Tamm-Horsfall protein/uromodulin in COX-2-deficient mice increases their susceptibility to urinary tract infections. Am. J. Physiol. Renal Physiol. 289, F49-F60 (2005).

190. Chiu, I. M. et al. Bacteria activate sensory neurons that modulate pain and inflammation. Nature 501 52-57 (2013).

191. Weinstock, J. V. Substance P and the regulation of inflammation in infections and inflammatory bowel disease. Acta Physiol. 213, 453-461 (2015).

192. Benson, M. et al. Interleukin 6 response to urinary tract infection in childhood. Pediatr. Infect. Dis. J. 13 612-616 (1994)

193. Davidoff, R., Yamaguchi, R., Leach, G. E., Park, E. \& Lad, P. M. Multiple urinary cytokine levels of bacterial cystitis. J. Urol. 157, 1980-1985 (1997).

194. Hang, L. et al. Macrophage inflammatory protein-2 is required for neutrophil passage across the epithelia barrier of the infected urinary tract. J. Immunol. 162, 3037-3044 (1999).

195. Ingersoll, M. A., Kline, K. A., Nielsen, H. V. \& Hultgren, S. J. G-CSF induction early in uropathogenic Escherichia coli infection of the urinary tract modulates host immunity. Cell Microbiol. 10, 2568-2578 (2008).

196. Schiwon, M. et al. Crosstalk between sentinel and helper macrophages permits neutrophil migration into infected uroepithelium Cell 156, 456-468 (2014).

197. Lin, A. E. et al. Role of hypoxia inducible factor-1 alpha (HIF-1 alpha) in innate defense against uropathogenic Escherichia coli infection. PLoS Pathog. 11, e 1004818 (2015).

198. Armbruster, C. E. Smith, S. N., Mody L \& Mobley, H. L. T. Urine cytokine and chemokine levels predict urinary tract infection severity independent of uropathogen, urine bacterial burden, host genetics, and host age. Infect. Immun. 86, e00327-18 (2018).

199. Yu, L. et al. Mucosal infection rewires TNFa signaling dynamics to skew susceptibility to recurrence. eLife $\mathbf{8}$, e46677 (2019).

200. Metcalf, D. \& Nicola, N. A. Proliferative effects of purified granulocyte colony-stimulating factor (G-CSF) 
on normal mouse hemopoietic cells. J. Cell Physiol. 116, 198-206 (1983).

201. Barreda, D. R., Hanington, P. C. \& Belosevic, M Regulation of myeloid development and function by colony stimulating factors. Dev. Comp. Immunol. 28 509-554 (2004).

202. Marshall, J. C. The effects of granulocyte colonystimulating factor in preclinical models of infection and acute inflammation. Shock 24 (Suppl. 1), 120-129 (2005).

203. Isaacson, B. et al. Stromal cell-derived factor 1 mediates immune cell attraction upon urinary tract infection. Cell Rep. 20, 40-47 (2017).

204. Zychlinsky Scharff, A. et al. Sex differences in IL-17 contribute to chronicity in male versus female urinary tract infection. JCl Insight 5, e122998 (2019).

205. Sivick, K. E., Schaller, M. A., Smith, S. N. \& Mobley, H. L. The innate immune response to uropathogenic Escherichia coli involves IL-17A in a murine model of urinary tract infection. J. Immunol. 184, 2065-2075 (2010).

206. Wu, J. et al. A highly polarized TH2 bladder response to infection promotes epithelial repair at the expense of preventing new infections. Nat. Immunol. 21 , 671-683 (2020)

207. Hagan, E. C., Lloyd, A. L., Rasko, D. A., Faerber, G. J. \& Mobley, H. L. Escherichia coli global gene expression in urine from women with urinary tract infection. PLoS Pathog. 6, e1001187 (2010)

208. Lindstedt, R. et al. The receptor repertoire defines the host range for attaching Escherichia coli strains that recognize globo-A. Infect. Immun. 59, 1086-1092 (1991).

209. Johanson, I.-M., Plos, K., Marklund, B.-I. \& Svanborg, C Pap, papG and prsG DNA sequences in Escherichia coli from the fecal flora and the urinary tract. Microb. Pathog. 15, 121-129 (1993).

210. Hultgren, S. J., Porter, T. N., Schaeffer, A. J. \& Duncan, J. L. Role of type 1 pili and effects of phase variation on lower urinary tract infections produced by Escherichia coli. Infect. Immun. 50, 370-377 (1985).

211. Svanborg-Eden, C. et al. Bacterial virulence versus host resistance in the urinary tracts of mice. Infect. Immun. 55, 1224-1232 (1987).

212. Wold, A. E. et al. Secretory immunoglobulin A carries oligosaccharide receptors for Escherichia coli type 1 fimbrial lectin. Infect. Immun. 58, 3073-3077 (1990)

213. Wu, X. R., Sun, T. T. \& Medina, J. J. In vitro binding of type 1 -fimbriated Escherichia coli to uroplakins la and Ib: relation to urinary tract infections. Proc. Natl Acad. Sci. USA 93, 9630-9635 (1996).

214. Malaviya, R., Gao, Z., Thankavel, K., van der Merwe, P. A. $\&$ Abraham, S. N. The mast cell tumor necrosis factor alpha response to FimH-expressing Escherichia coli is mediated by the glycosylphosphatidylinositolanchored molecule CD48. Proc. Natl Acad. Sci. USA 96, 8110-8115 (1999).

215. Pak, J., Pu, Y., Zhang, Z. T., Hasty, D. L. \& Wu, X. R. Tamm-Horsfall protein binds to type 1 fimbriated Escherichia coli and prevents $E$. coli from binding to uroplakin la and Ib receptors. J. Biol. Chem. 276. 9924-9930 (2001)

216. Xie, B. et al. Distinct glycan structures of uroplakins $\mathrm{la}$ and $\mathrm{lb}$ : structural basis for the selective binding of FimH adhesin to uroplakin la. J. Biol. Chem. 281 14644-14653 (2006).

217. Eto, D. S., Jones, T. A., Sundsbak, J. L. \& Mulvey, M. A Integrin-mediated host cell invasion by type 1-piliated uropathogenic Escherichia coli. PLoS Pathog. 3, e100 (2007).

218. Anderson, G. G. et al. Intracellular bacterial biofilm like pods in urinary tract infections. Science 301 . 105-107 (2003).

219. Wright, K. J., Seed, P. C. \& Hultgren, S. J. Development of intracellular bacterial communities of uropathogenic Escherichia coli depends on type 1 pili. Cell Microbiol. 9, 2230-2241 (2007).

220. Rosen, D. A., Hooton, T. M., Stamm, W. E. Humphrey, P. A. \& Hultgren, S. J. Detection of intracellular bacterial communities in human urinary tract infection. PLoS Med. 4, e329 (2007)

221. Klumpp, D. J. et al. Uropathogenic Escherichia coli induces extrinsic and intrinsic cascades to initiate urothelial apoptosis. Infect. Immun. 74, 5106-5113 (2006).

222. Song, J. et al. A novel TLR4-mediated signaling pathway leading to IL-6 responses in human bladder epithelial cells. PLoS Pathog. 3, e60 (2007).

223. Thumbikat, P. et al. Bacteria-induced uroplakin signaling mediates bladder response to infection. PLoS Pathog. 5, e1000415 (2009).
224. Bishop, B. L. et al. Cyclic AMP-regulated exocytosis of Escherichia coli from infected bladder epithelial cells. Nat. Med. 13, 625-630 (2007).

225. Malaviya, R., Ikeda, T., Ross, E. \& Abraham, S. N Mast cell modulation of neutrophil influx and bacterial clearance at sites of infection through TNF-alpha. Nature 381, 77-80 (1996).

226. Yano, H., Wershil, B. K., Arizono, N. \& Galli, S. J. Substance P-induced augmentation of cutaneous vascular permeability and granulocyte infiltration in mice is mast cell dependent. J. Clin. Invest. $\mathbf{8 4}$ 1276-1286 (1989).

227. Abraham, S., Shin, J. \& Malaviya, R. Type 1 fimbriated Escherichia coli-mast cell interactions in cystitis. J. Infect. Dis. 183 (Suppl. 1), S51-S55 (2001).

228. Aronson, M., Medalia, O., Amichay, D. \& Nativ, O. Endotoxin-induced shedding of viable uroepithelial cells is an antimicrobial defense mechanism. Infect. Immun. 56, 1615-1617 (1988).

229. Mulvey, M. A., Schilling, J. D. \& Hultgren, S. J. Establishment of a persistent Escherichia coli reservoir during the acute phase of a bladder infection. Infect. Immun. 69, 4572-4579 (2001).

230. Choi, H. W. et al. Loss of bladder epithelium induced by cytolytic mast cell granules. Immunity $\mathbf{4 5}$, 1258-1269 (2016).

231. O'Brien, V. P. et al. A mucosal imprint left by prior Escherichia coli bladder infection sensitizes to recurrent disease. Nat. Microbiol. 2, 16196 (2016).

232. Hannan, T. J. et al. Inhibition of cyclooxygenase-2 prevents chronic and recurrent cystitis. Env. Bio Med. 1, 46-57 (2014)

233. O'Brien, V. P., Dorsey, D. A., Hannan, T. J. \& Hultgren, S. J. Host restriction of Escherichia coli recurrent urinary tract infection occurs in a bacteria strain-specific manner. PLoS Pathog. 14, e 1007457 (2018).

234. Kurt-Jones, E. A. et al. Pattern recognition receptors TLR4 and CD14 mediate response to respiratory syncytial virus. Nat. Immunol. 1, 398-401 (2000).

235. O'Neill, L. A., Golenbock, D. \& Bowie, A. G. The history of Toll-like receptors - redefining innate immunity. Nat. Rev. Immunol. 13, 453-460 (2013).

236. Patra, R., Chandra Das, N. \& Mukherjee, S. Targeting human TLRs to combat COVID-19: a solution? J. Med. Virol. 93, 615-617 (2020).

237. Toelzer, C. et al. Free fatty acid binding pocket in the locked structure of SARS-CoV-2 spike protein. Science 370, 725-730 (2020).

238. Huang, Q. et al. Targeting inflammation and cytokine storm in COVID-19. Pharmacol. Res. 159 105051-105051 (2020).

239. Otto, G., Braconier, J., Andreasson, A. \& Svanborg, C. Interleukin- 6 and disease severity in patients with bacteremic and nonbacteremic febrile urinary tract infection. J. Infect. Dis. 179, 172-179 (1999).

240. Fraser, D., Patterson, E., Daley, M. \& Cepinskas, G. Case Report: Inflammation and endothelial injury profiling of COVID-19 pediatric multisystem inflammatory syndrome (MIS-C). Front. Pediatr. 9 597926 (2021).

241. Carey, A. J. et al. Uropathogenic Escherichia coli engages CD14-dependent signaling to enable bladdermacrophage-dependent control of acute urinary tract infection. J. Infect. Dis. 213, 659-668 (2016).

242. Jones-Carson, J., Balish, E. \& Uehling, D. T. Susceptibility of immunodeficient gene-knockout mice to urinary tract infection. J. Urol. 161, 338-341 (1999).

243. Wang, C. et al. NOD2 is dispensable for ATG16L1 deficiency-mediated resistance to urinary tract infection. Autophagy 10, 331-338 (2014).

244. Lattenist, L et al. The lectin like domain of thrombomodulin is involved in the defence against pyelonephritis. Thromb. Res. 136, 1325-1331 (2015)

245. Greve, A. S. et al. P2X1, P2X4, and P2X7 receptor knock out mice expose differential outcome of sepsis induced by alpha-haemolysin producing Escherichia coli. Front. Cell Infect. Microbiol. 7, 113 (2017).

246. Wang, C. et al. Atg16L1 deficiency confers protection from uropathogenic Escherichia coli infection in vivo. Proc. Natl Acad. Sci. USA 109, 11008-11013 (2012).

247. Li, K. et al. C5aR1 promotes acute pyelonephritis induced by uropathogenic E. coli. JCI Insight 2 , e97626 (2017).

248. Dessing, M. C. et al. S100A8/A9 is not involved in host defense against murine urinary tract infection. PLOS ONE 5, e 13394 (2010).

249. Ragnarsdottir, B. et al. Reduced Toll-like receptor 4 expression in children with asymptomatic bacteriuria. J. Infect. Dis. 196, 475-484 (2007).

250. Tabel, Y., Berdeli, A. \& Mir, S. Association of TLR2 gene Arg753Gln polymorphism with urinary tract infection in children. Int. J. Immunogenet. 34, 399-405 (2007).

251. Javor, J. et al. Genetic variations of interleukin-8, CXCR 1 and CXCR2 genes and risk of acute pyelonephritis in children. Int. J. Immunogenet. 39 , 338-345 (2012).

252. Cheng, C. H., Lee, Y. S., Tsau, Y. K. \& Lin, T. Y. Genetic polymorphisms and susceptibility to parenchymal renal infection among pediatric patients. Pediatr. Infect. Dis. J. 30, 309-314 (2011).

253. Georgitsi, M. D. et al. Individualized significance of the $-251 \mathrm{~A} / \mathrm{T}$ single nucleotide polymorphism of interleukin-8 in severe infections. Eur. J. Clin. Microbiol. Infect. Dis. 35, 563-570 (2016).

254. Hussein, A. et al. Impact of cytokine genetic polymorphisms on the risk of renal parenchymal infection in children. J. Pediatr. Urol. 13, 593. e1-593.e10 (2017).

255. Cheng, C. H., Lee, Y. S., Chang, C. J., Lin, J. C. \& Lin, T. Y. Genetic polymorphisms in inflammasome-dependent innate immunity among pediatric patients with severe renal parenchymal infections. PLOS ONE 10, e0140128 (2015)

256. Hughes, L. B. et al. Genetic risk factors for infection in patients with early rheumatoid arthritis. Genes Immun. 5, 641-647 (2004).

257. Karoly, E. et al. Heat shock protein 72 (HSPA1B) gene polymorphism and Toll-like receptor (TLR) 4 mutation are associated with increased risk of urinary tract infection in children. Pediatr. Res. 61, 371-374 (2007).

258. Schwaderer, A. L et al. Polymorphisms in alphadefensin-encoding DEFA1 A3 associate with urinary tract infection risk in children with vesicoureteral reflux. J. Am. Soc. Nephrol. 27, 3175-3186 (2016).

259. Yim, H. E., Bae, I. S., Yoo, K. H., Hong, Y. S. \& Lee, J. W. Genetic control of VEGF and TGF-beta 1 gene polymorphisms in childhood urinary tract infection and vesicoureteral reflux. Pediatr. Res. 62, 183-187 (2007).

260. Akil, I. et al. Assessment of Toll-like receptor-4 gene polymorphism on pyelonephritis and renal scar. Int. J. Immunogenet. 39, 303-307 (2012).

261. Bayram, M. T., Soylu, A., Ates, H., Kizildag, S. \& Kavukcu, S. TLR-4 polymorphisms and leukocyte TLR-4 expression in febrile UTI and renal scarring. Pediatr. Nephrol. 28, 1827-1835 (2013).

262. Gond, D. P., Singh, S. \& Agrawal, N. K. Testing an association between TLR4 and CXCR1 gene polymorphisms with susceptibility to urinary tract infection in type 2 diabetes in north Indian population. Gene 641, 196-202 (2018).

263. Karananou, P. et al. The role of TLR4 Asp299Gly and TLR4 Thr399lle polymorphisms in the pathogenesis of urinary tract infections: first evaluation in infants and children of Greek origin. J. Immunol. Res. 2019. 6503832 (2019).

264. Aslan, S. et al. Vitamin D receptor gene polymorphism in children with urinary tract infection. Pediatr. Nephrol. 27, 417-421 (2012)

\section{Acknowledgements}

The authors gratefully acknowledge the support of the Swedish Research Council, Swedish Cancer Society, HJ Forssman Foundations, Medical Faculty (Lund University), Royal Physiographic Society, Network of Excellence: Infect-ERA and ALF grants from the Medical Faculty and Regional Laboratories (Labmedicin Skåne), the European Union's Horizon 2020 research and innovation programme (grant no. 954360) for support to the laboratory infrastructure.

\section{Author contributions}

I.A., D.B., M.L.Y.W., T.R. and C.S. researched data for the article and wrote the manuscript. I.A., D.B., M.L.Y.W., C.S., T.H.T., S.M.C. and C.S. made substantial contributions to discussions of the content and I.A., D.B., M.L.Y.W. and C.S. reviewed and edited the manuscript before submission.

\section{Competing interests}

Patents have been filed for the use of the NIpD protein and IRF7 siRNA as immune modulators and for the use of IL-1R antagonists in the treatment of cystitis. The rights to develop these patents are held by Selectlmmune Pharma, where the scientists I.A., D.B., T.H.T., M.L.Y.W. and C.S. hold shares. T.R. and S.M.C. declare no competing interests.

\section{Publisher's note}

Springer Nature remains neutral with regard to jurisdictional claims in published maps and institutional affiliations.

(c) Springer Nature Limited 2021 